OPEN ACCESS

Edited by:

Anna-Louise Reysenbach, Portland State University,

United States

Reviewed by:

Changyi Zhang,

University of Illinois

at Urbana-Champaign, United States

Wenyuan Han,

Huazhong Agricultural University,

China

*Correspondence:

Senthil E. Prasad

esprasad@imtech.res.in

Krishan Gopal Thakur

krishang@imtech.res.in

${ }^{\dagger}$ Present address:

Chandni Sidhu,

Department of Molecular Ecology,

Max Planck Institute for Marine

Microbiology, Bremen, Germany

Specialty section:

This article was submitted to

Biology of Archaea,

a section of the journal

Frontiers in Microbiology

Received: 12 March 2020

Accepted: 07 August 2020

Published: 01 September 2020

Citation:

Verma DK, Vasudeva G, Sidhu C,

Pinnaka AK, Prasad SE and

Thakur KG (2020) Biochemical and Taxonomic Characterization

of Novel Haloarchaeal Strains and Purification of the Recombinant Halotolerant $\alpha$-Amylase Discovered

in the Isolate.

Front. Microbiol. 11:2082.

doi: 10.3389/fmicb.2020.02082

\section{Biochemical and Taxonomic} Characterization of Novel Haloarchaeal Strains and Purification of the Recombinant Halotolerant $\alpha$-Amylase Discovered in the Isolate

\author{
Dipesh Kumar Verma1, Gunjan Vasudeva², Chandni Sidhu²t, Anil K. Pinnaka², \\ Senthil E. Prasad ${ }^{3 *}$ and Krishan Gopal Thakur ${ }^{1 *}$
}

${ }^{1}$ G. N. Ramachandran Protein Centre, Structural Biology Laboratory, Council of Scientific and Industrial Research-Institute of Microbial Technology, Chandigarh, India, ${ }^{2}$ MTCC-Microbial Type Culture Collection and Gene Bank, CSIR-Institute of Microbial Technology, Chandigarh, India, ${ }^{3}$ Biochemical Engineering Research and Process Development Centre, Council of Scientific and Industrial Research-Institute of Microbial Technology, Chandigarh, India

Haloarchaea are salt-loving archaea and potential source of industrially relevant halotolerant enzymes. In the present study, three reddish-pink, extremely halophilic archaeal strains, namely wsp1 (wsp-water sample Pondicherry), wsp3, and wsp4, were isolated from the Indian Solar saltern. The phylogenetic analysis based on $16 S$ rRNA gene sequences suggests that both wsp3 and wsp4 strains belong to Halogeometricum borinquense while wsp1 is closely related to Haloferax volcanil species. The comparative genomics revealed an open pangenome for both genera investigated here. Whole-genome sequence analysis revealed that these isolates have multiple copies of industrially/biotechnologically important unique genes and enzymes. Among these unique enzymes, for recombinant expression and purification, we selected four putative $\alpha$-amylases identified in these three isolates. We successfully purified functional halotolerant recombinant Amy2, from wsp1 using pelB signal sequencebased secretion strategy using Escherichia coli as an expression host. This method may prove useful to produce functional haloarchaeal secretory recombinant proteins suitable for commercial or research applications. Biochemical analysis of Amy2 suggests the halotolerant nature of the enzyme having maximum enzymatic activity observed at $1 \mathrm{M}$ $\mathrm{NaCl}$. We also report the isolation and characterization of carotenoids purified from these isolates. This study highlights the presence of several industrially important enzymes in the haloarchaeal strains which may potentially have improved features like stability and salt tolerance suitable for industrial applications.

Keywords: haloarchaea, amylase, pangenome, carotenoids, halotolerant enzyme

\section{INTRODUCTION}

The extremely halophilic archaea have adapted to bloom even in harsh environmental conditions such as high salinity, desiccation, and intense solar radiations (Mormile et al., 2003; GundeCimerman et al., 2005; Schubert et al., 2010; Stan-Lotter and Fendrihan, 2015; Winters et al., 2015). These microorganisms require at least $1.5-2.5 \mathrm{M} \mathrm{NaCl}$ concentration for their viability and typically 
grow optimally in $3.5 \mathrm{M} \mathrm{NaCl}$ concentrations (Ollivier et al., 1994). Haloarchaea commonly resides in hypersaline environments such as salt lakes, salterns, heavily salted hides, meats, fish, and sauces (Radax et al., 2001; Gruber et al., 2004; Stan-Lotter and Fendrihan, 2015). Adaptation in such extreme and diverse environments makes their genome highly rich in multiple essential genes that are absent in other microorganisms (Papke et al., 2015). This essential new haloarchaeal gene pool analysis has the potential to uncover many industrially important proteins and enzymes. So, it is imperative to perform pangenome or comparative genomics analysis to understand the genetic evolution and distribution of unique and conserved genes in these microbes that help them to survive in harsh conditions (Kim et al., 2018). As aerophilic mesophiles, many haloarchaea are easy to grow in the laboratory conditions, making them one of the most extensively studied archaeal groups and thus, leading to the development of a variety of biochemical, genetic and genomic tools for better understanding of several diverse haloarchaeal species (Soppa, 2006).

Besides having the ability to thrive in high salt conditions, haloarchaea possess diverse physiologies including alkaliphiles, facultative thermophiles, thermoalkaliphiles, and psychrotolerant species (Bowers et al., 2009; Bowers and Wiegel, 2011) and diverse metabolic strategies. These interesting features make them ideal organisms for understanding archaeal biology (Falb et al., 2008). In addition, the genetic basis of these microbes to flourish in hypersaline environments may provide crucial insights to develop salt-tolerant plants for growth in currently non-arable land (Flowers and Colmer, 2015).

Halophiles produce a range of unique and stable biomolecules of commercial applications including (1) hydrolytic enzymes like gelatinases, proteases, lipases, DNAases, xylanases, and amylase. Exo-enzymes from these organisms with polymer degrading ability is of great interest in many industrial processes where high salt concentration would cause enzymatic inhibition (Oren, 2010). These unique features make haloarchaeal enzymes very useful in commercial industries such as baking industries (Oren, 2010), starch liquefaction (Chi et al., 2010), detergent industries, maltose production, etc. (Singh and Singh, 2017). (2) Membrane proteins such as bacteriorhodopsin, commercially recognized for its use in artificial retina, holograms, photoelectrical devices, optical computing, etc. (3) Biodegradable polymers such as polyhydroxyalkanoates (PHAs), produced by many haloarchaea can be used as an alternative to non-degradable plastics (Schiraldi et al., 2002; Oren, 2010). (4) Carotenoids: under certain growth conditions, microbial cells are known to accumulate different pigments, having several commercial applications (Britton, 1995; Vershinin, 1999). Carotenoids are one such class of pigments produced by microbes and plants which play a major role in protecting cells against photo-oxidative damage and hence have vital applications in the environment (Zhang et al., 2014), food and nutrition (Vilchez et al., 2011), disease control (Fiedor and Burda, 2014), and as potent antimicrobial agent (Narsing Rao et al., 2017). Haloarchaea are one of the richest sources of carotenoids compared to other microorganisms (Yatsunami et al., 2014; Montero-Lobato et al., 2018; Giani et al., 2019). The main component of the haloarchaeal carotenoid pool is bacterioruberin which reportedly has more antioxidant properties compared to plant $\beta$-carotenes (Yatsunami et al., 2014). Other than bacterioruberin, they also contain isopentenyl dehydrodopin, lycopene, and phytoene in trace amounts (Yatsunami et al., 2014).

In the present study, we isolated and characterized three haloarchaeal strains namely wsp1, wsp3, and wsp4 from the Pondicherry solar lakes, one of the high salt containing areas of the Indian solar salterns. We performed a polyphasic taxonomic classification of these isolated strains using wholegenome sequencing and biochemical assays. Using comparative genomic analysis, we identified the core, accessory, and unique gene pool of haloarchaeal proteins. We identified several industrially important enzymes encoded in the genomes of these strains. We report the expression, and purification of a halotolerant recombinant starch degrading enzyme i.e., $\alpha$-amylase Amy2 isolated from Haloferax strain wsp1 having distinct sequence and structural features. All the strains reported here were colored and genome analysis suggested the presence of carotene biosynthesis genes in their genomes. We further report the isolation and characterization of carotenoids produced by these strains.

\section{RESULTS}

\section{Isolation and Taxonomic Characterization of Haloarchaeal Isolates}

All three strains were isolated from solar saltern samples collected from Marakkanam solar salterns, India $\left(12^{\circ} 11^{\prime} 13.0272^{\prime \prime} \mathrm{N}\right.$ and $79^{\circ} 55^{\prime} 40.4220^{\prime \prime} \mathrm{E}$ ) using the dilution-plate technique on the Halovibrio agar medium as described previously (Verma et al., 2019). Briefly, on agar plates, the reddish-pink opaque convex colonies, 1-2 $\mathrm{mm}$ in diameter appeared in 7 days. The growth of wsp isolates were screened from 12 to $42^{\circ} \mathrm{C}$, which suggested that they have optimum growth at $37^{\circ} \mathrm{C}$. The positive growth was observed on media containing 3-5 $\mathrm{M} \mathrm{NaCl}$ (Figure 1A), whereas no growth was observed on $0.3-2 \mathrm{M} \mathrm{NaCl}$ concentrations. Transmission electron microscopic images suggested that wsp1, wsp3, and wsp4 have pleomorphic morphology, and compared to wsp1, both wsp3, and wsp4 isolates are highly vacuolated (Figure 1B and Supplementary Figure S1).

\section{Comparative Genome Analyses of wsp1, wsp3, and wsp4}

Comparison of both 16S rRNA and whole-genome sequences suggested that all three isolates are novel strains that belong to Haloferax and Halogeometricum genera. These results were further confirmed by calculating ANI (Average nucleotide index) and digital DNA-DNA hybridization scores where the observed values were higher than the accepted cut-off values (for ANI > 95\% and for DNA-DNA hybridization $>91 \%$ ) for novel species (Supplementary Tables S1, S2). The phylogenetic analysis based on $16 \mathrm{~S}$ rRNA sequencing data suggested that wsp1 is closely related to Haloferax volcanii 
A

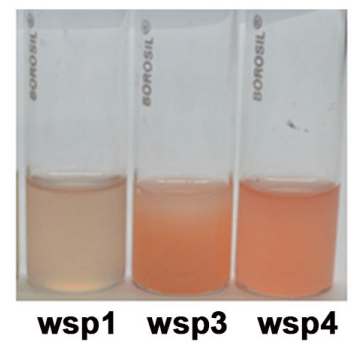

B

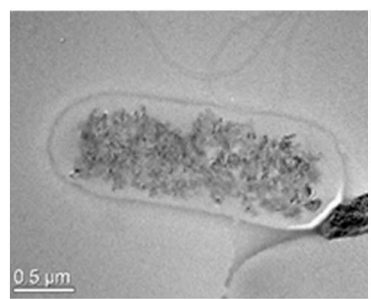

H. volcanii wsp1

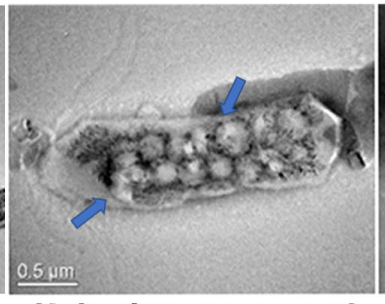

H. borinquense wsp3

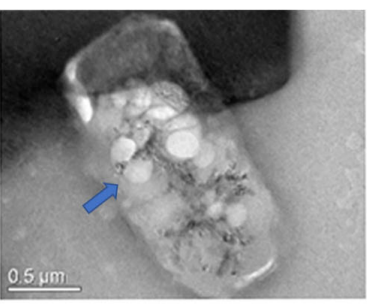

H. borinquense wsp4
C

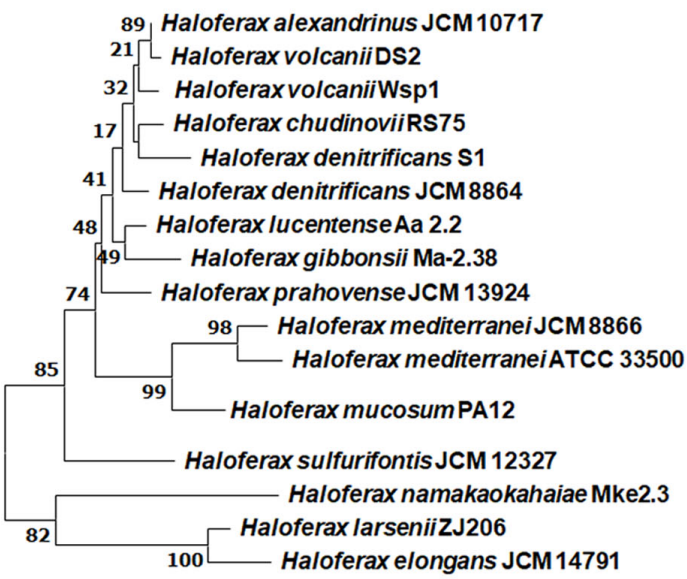

89. Haloferax alexandrinus JCM 10717

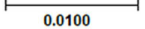

E
E

D

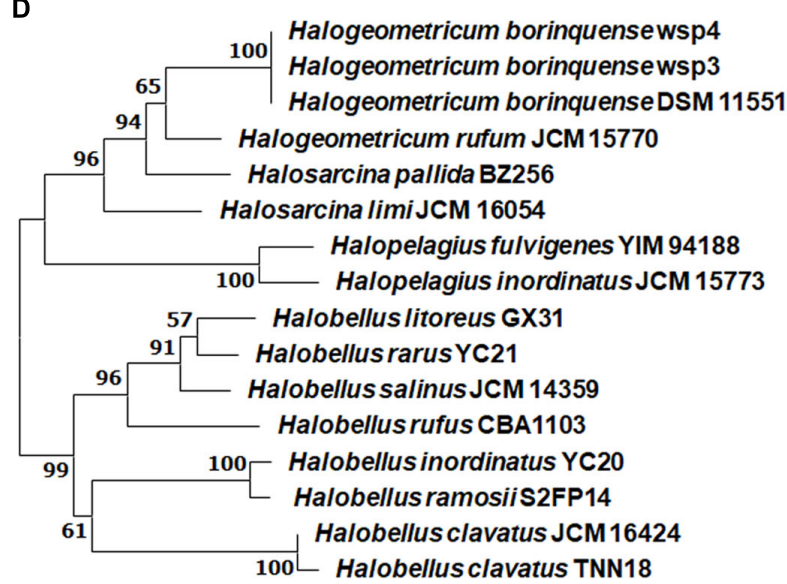

Halogeometricum borinquensewsp4 Halogeometricum borinquensewsp3 Halogeometricum borinquense DSM 11551

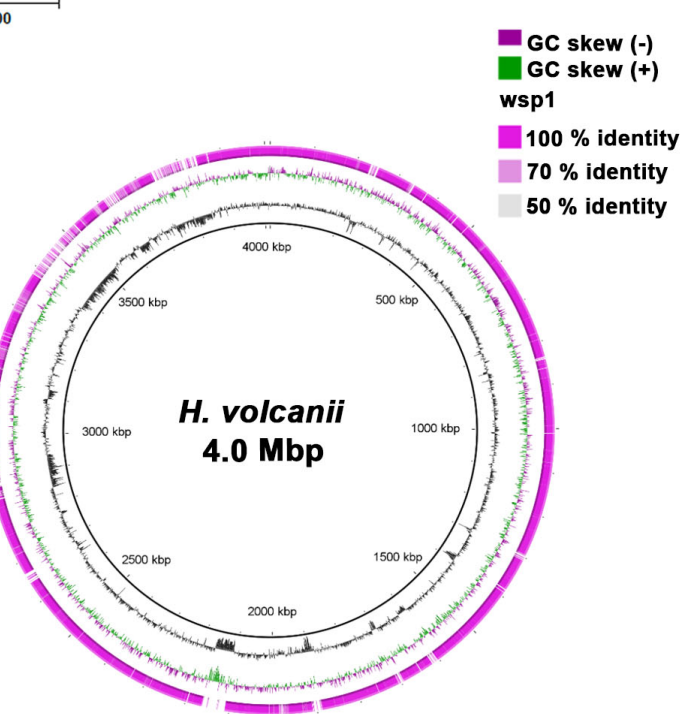

FIGURE 1 | Morphological and taxonomic characterization of the haloarchaeal isolates. (A) Wild type culture of haloarchaeal isolates in light reddish-pink color suggesting high carotenoid production. (B) TEM images suggest that wsp3 and wsp4 are highly vacuolated (shown in blue arrow) compared with wsp1 (C,D) The16S rRNA based phylogenetic analysis suggested that wsp1 strain is closely related to $H$. volcanii DS2 while both wsp3 and wsp4 are closely related to H. borinquense DSM 11551. (E,F) Genomic maps of the isolates and their reference species constructed using the BRIG tool. The inner black rings show the coordinates in scale and total genome size of the reference sequence, with black histogram representing GC content and purple/green histograms representing GC deviations. In the panel, (E) outermost ring in magenta color represents the genome map of wsp1 strain and in the panel, (F) blue color represents wsp3 genome map while wsp4 genome map is represented in magenta color.

DS2 and Haloferax chudinovii RS75 strains sharing 99\% sequence similarity. Both wsp3 and wsp4 are closely related to Halogeometricum borinquense DSM 11551 strain sharing
$>99 \%$ sequence identity (Figures 1C,D). The genus Haloferax was first described by Torreblanca et al. (1986) and currently comprises twelve species, namely $H$. sulfurifontis, $H$. mucosum, 
$H$. mediterranei, $H$. denitrificans, $H$. prahovense, $H$. larsenii, $H$. gibbonsi, $H$. elongans, $H$. alexandrinus, $H$. lucentense, $H$. volcanii, and $H$. massiliensis. On the other hand, genus Halogeometricum was first described by Montalvo-Rodriguez et al. (1998) and comprises four species, namely $H$. pallidum, $H$. borinquense, $H$. limi, and H. rufum. H. volcanii DS2, and H. borenquencis DSM 11551 are the type strains of Haloferax and Halogeometricum genus, respectively. The draft genome sequences of wsp1, wsp3, and wsp4 comprized of $37,07,582 \mathrm{bp}(3.7 \mathrm{Mb}), 28,18,554 \mathrm{bp}$ (2.8 Mb) and 39, 97,080 bp (3.9 Mb) with 4047, 3040, and 4257 annotated coding sequences (CDS). The GC content of wsp1, wsp3, and wsp4 were 66.1, 61.0, and 59.7\%, respectively. For further analysis, we compared wsp1 genome sequences with $H$. volcanii DS2 and both wsp3 and wsp4 genomes with the H. borinquense DSM 11551. Genome circular map built by using BLAST Ring Image Generator (BRIG) tool (Alikhan et al., 2011), revealed that wsp3 has high sequence similarity with both wsp4 and $H$. borinquense DSM 11551 genomes except one highly variable region of about $1 \mathrm{Mbp}$ (Figure 1F).

\section{Pangenome Analysis}

During evolution, microbes acquired several genes that facilitate their growth and survival. The important genes in this list include genes responsible for cell signaling, metabolic regulators, antibacterial proteins, ion transporters, etc. To understand the environmental effect on gene pool variation, we performed a pangenome analysis of wsp samples with their closely related species using the Bacterial Pan Genome Analysis (BPGA) pipeline (Chaudhari et al., 2016). The original pangenome concept was developed by Tettelin et al. (2005) and it describes the total pool of genetic material comprized of all members of a species. The pangenome consists of three different groups known as the core, accessory, and unique genomes. The core genome consists of common genes that are present in all individuals, accessory or dispensable genome containing shell genes present in few individuals and a unique genome contains genes that are specifically present only in an individual member (Tettelin et al., 2005; Wolf et al., 2012; Vernikos et al., 2015). The outcomes of the pangenome analysis are discussed in the following sections.

\section{Clusters of Orthologous Groups (COG) Distribution Plots}

The whole-genome sequences of Haloferax and Halogeometricum members were retrieved from NCBI (National Center for Biotechnology Information) database. The functional annotation was carried out using Rapid Annotation using Subsystem Technology webserver (Aziz et al., 2008). The distribution of the archaeal clusters of orthologous groups (arCOG) of Haloferax and Halogeometricum genera along with our isolates with their biological functions are shown in Figures 2A,B. The potential functions of the unique genes from both genera appear to be widespread and linked with many different cellular functions such as cell motility, post-translational modifications, chaperones, signal transduction mechanisms, and many genes with unknown function. On the other hand, the accessory genes identified are mainly associated with carbohydrate transport, inorganic ion transport, and several genes with unknown function. The core genome consists of the genes involved in translation regulation, ribosomal structure and biogenesis, replication, recombination and repair proteins, energy production and conversion, coenzyme transport and metabolism, lipid transport and metabolism and nucleotide transport and metabolism.

\section{Pan and Core Genome Plots}

The comparative genome analysis revealed an open pangenome for both genera investigated here (Figures 2C,D) as the number of accessory and unique genes are increasing with the addition of new genomes. For the genus Haloferax, the pangenome and core genome contain 7950 and 1885 genes, respectively (Figure 2C). For the genus Halogeometricum, the pangenome and core genome contain 7197 and 1874 genes, respectively (Figure 2D). Similar findings were reported for the pangenome based analysis in other studies as well (Capes et al., 2012; Becker et al., 2014; Borchert et al., 2017). The pangenome analysis revealed that wsp1, wsp3, and wsp4 contain 246, 530, and 106 unique genes in their genomes. These unique genes were further annotated using online server Web Services for Metagenomic Analysis (WEBMGA) (Wu et al., 2011). We found multiple unique clusters including genes potentially encoding cation efflux proteins, integrases, and proteins potentially involved in multidrug resistance. The annotated genes also included commercially useful salt-tolerant enzymes like amylases, alcohol dehydrogenases, sulphataes, esterase's, etc.

The size of pangenome is larger than the core genome and is increasing with the addition of the new genomes suggesting both the genera investigated here have open pangenome. The current study is important for understanding the genomic variations and distribution of accessory genes providing survival advantage to the haloarchaeal strains in adverse conditions.

\section{Biochemical Characterization of Haloarchaeal Isolates}

Polyphasic taxonomic characterization were studied according to the methods in the proposed minimal standards for description of new taxa in the order Halobacteriales (Table 1A; Grant and Larsen, 1989; Oren et al., 1997). Biochemical characterization suggested that all three isolates were positive for the catalase test and negative for urease, lipase, and Voges-Proskauer tests. All three strains were also negative for acid production, casein hydrolysis, and hydrogen sulfide production. We also performed enzymatic screening which involved in amino-acid biosynthesis pathways and found that all three were negative for lysine decarboxylase, arginine decarboxylase, aesulin hydrolysis, and ornithine decarboxylase.

Wsp3 and wsp4 strains had many similar enzymatic features such as both were positive for citrate utilization, oxidase test, and methyl red test. Besides these similarities, some variations were also observed e.g., both $H$. borinquense DSM 11551 and wsp3 are positive for gelatin liquefaction and indole production while wsp4 is negative. We also found that wsp3 is unable to reduce nitrate, unlike $H$. borinquense DSM 11551 and wsp4. Genome analysis suggests that both H. borinquense DSM 11551 

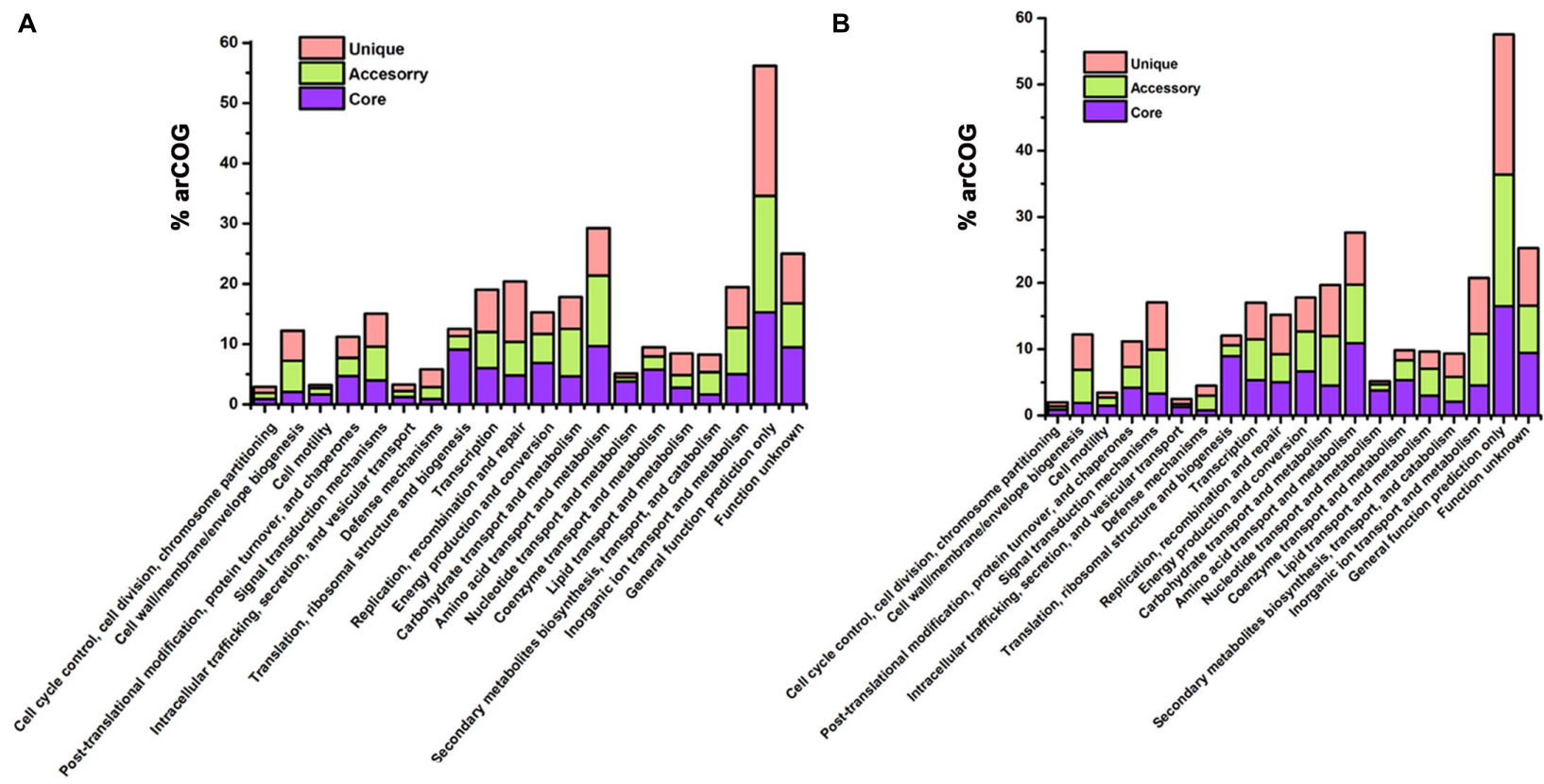

C

D
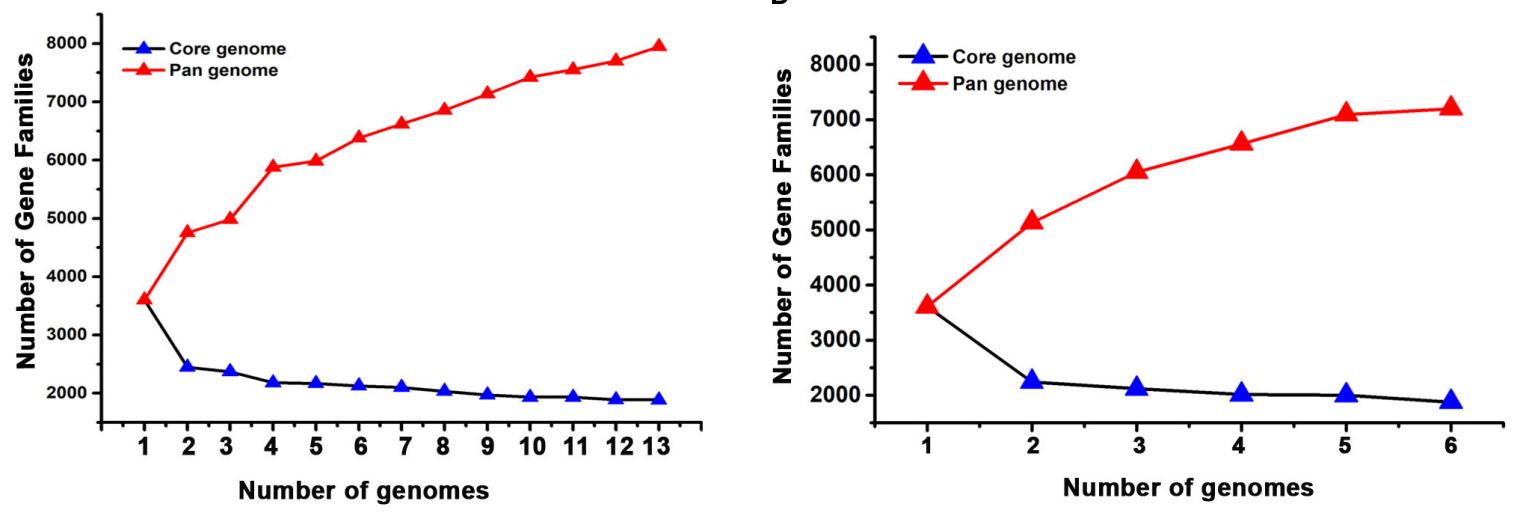

FIGURE 2 | Archaeal clusters of orthologous groups (arCOG) analysis of the genomes. Comparison of the COG distribution between the core, accessory and unique genes of the (A) thirteen species belonging to genus Haloferax including wsp1 and (B) four species belonging to genus Halogeometricum including wsp3 and wsp4 have been analyzed using default parameters of BPGA pipeline. The arCOG categories are indicated on the $X$-axis and the percentage of the genes present in each category of the arCOG classes is indicated on the $Y$-axis. (C,D) The Core and pangenome plots of genera Haloferax and Halogeometricum, respectively. Red and blue colored lines indicate the change in the number of pangenome and core genome gene groups added sequentially to the genome.

and wsp4 encode nitrate reductase gene which is missing in the wsp3 genome. Similarly, we also found a copy of the nitrate reductase gene in wsp1 genome, which reduces nitrate, whereas it is missing in $H$. volcanii DS2 which is negative for nitrate utilization.

\section{Carbon Source Utilization}

Carbon source preferences of haloarchaeal isolates were identified by monitoring their growth in the presence of different carbon sources. Optical density-based assay results suggest that all three strains have similar preferences for dextrose while they were unable to utilize arabinose, rhamnose, aldonitol, inositol, inulin, and melibiose (Table 1B). Along with enzymebased biochemical tests, wsp3 and wsp4 had some similar and dissimilar preferences for carbon source utilization. Both wsp3 and wsp4 were positive for pyruvate and maltose utilization while negative for lactose and galactose utilization. Surprisingly, wsp3 alone was positive for three different carbon sources i.e., sucrose, cellobiose, and dulicitol while both $H$. borinquense DSM 11551 and wsp4 were negative. Similarly, wsp1 is not able to utilize sucrose and arabinose while its type strain $H$. volcanii DS2 is capable of utilizing both sugars.

Quantitative analysis of carbon source utilization shows that both wsp1 and wsp3 efficiently utilize galactose and maltose, respectively. Genome analysis suggested that both wsp1 and $H$. volcanii DS2, encode galactokinase enzyme which help them to utilize galactose as a carbon source (Anderson et al., 2011) while this enzyme is absent in both wsp3 and wsp4 strains. For maltose utilization, two alternative pathways have been proposed (Cibrario et al., 2016). The two essential enzymes 
TABLE 1 | (A) Biochemical test and (B) carbon source utilization test as an aid to the classification of haloarchaea.

\begin{tabular}{|c|c|c|c|}
\hline & Wsp3 & Wsp4 & Wsp1 \\
\hline \multicolumn{4}{|l|}{ (A) Biochemical test } \\
\hline Catalase test & + & + & + \\
\hline Oxidase Test & + & + & - \\
\hline Citrate utilization & + & + & - \\
\hline Production of acid & - & - & - \\
\hline Production of gas & - & - & - \\
\hline Lysine decarboxylase & - & - & - \\
\hline Methyl red test & + & + & - \\
\hline Voges-Proskauer test & - & - & - \\
\hline Nitrate reduction & - & + & + \\
\hline Casein hydrolysis & - & - & - \\
\hline Arginine decarboxylase & - & - & - \\
\hline Urease activity & - & - & - \\
\hline Ornithine decarboxylase & - & - & - \\
\hline Aesulin hydrolysis & + & + & + \\
\hline Gelatin Hydrolysis & + & - & - \\
\hline Indole production & + & - & - \\
\hline Lipase production & - & - & - \\
\hline \multicolumn{4}{|l|}{ (B) Carbon source } \\
\hline Dextrose & W & W & W \\
\hline Pyruvate & W & W & - \\
\hline Lactose & - & - & + \\
\hline Maltose & +++ & W & - \\
\hline Sucrose & W & - & - \\
\hline Galactose & - & - & +++ \\
\hline Arabinose & - & - & - \\
\hline Rhamanose & - & - & - \\
\hline Cellobiose & W & - & - \\
\hline Aldonitol & - & - & - \\
\hline Inositol & - & - & - \\
\hline Inulin & - & - & - \\
\hline Dulcitol & W & - & - \\
\hline Mannose & - & - & - \\
\hline Melibiose & - & - & - \\
\hline
\end{tabular}

+++ , highly positive; + , positive; -, negative, $W$, weakly positive.

of these pathways are malz ( $\alpha$-1, 4-glucosidase) and malA ( $\alpha$-amylase MalA). Genomic data analysis suggested that only wsp3 genome encodes for two different copies of $\alpha-1,4$ glucosidase enzyme while wsp 1 and wsp 4 only have an $\alpha$-amylase gene in their genomes. This probably explains why wsp3 can utilize maltose more efficiently compared to both wsp1 and wsp4.

\section{Antibiotic Susceptibility Profile}

Culture isolates were also screened for antibiotic resistance (Table 2). The analysis suggested that all three isolates were sensitive for novobiocin and resistant to penicillin, vancomycin, chloramphenicol, cephadroxil, lincomycin, cephalexin, ceftazidine, and cephadroxil. Surprisingly wsp3 had sensitivity for cefazolin and kanamycin while wsp1 and wsp4 were resistant to both the antibiotics like their type strains. The possible reason for kanamycin resistance in wsp1 and
TABLE 2 | Antibiotic susceptibility test of the isolates.

\begin{tabular}{lccc}
\hline Antibiotic sensitivity & wsp3 & wsp4 & wsp1 \\
\hline Novobiocin & $\mathrm{S}$ & $\mathrm{S}$ & $\mathrm{S}$ \\
Cefazolin & $\mathrm{S}$ & $\mathrm{R}$ & $\mathrm{R}$ \\
Kanamycin & $\mathrm{S}$ & $\mathrm{R}$ & $\mathrm{R}$ \\
Bacitracin & $\mathrm{I}$ & $\mathrm{R}$ & $\mathrm{R}$ \\
Penicillin & $\mathrm{R}$ & $\mathrm{R}$ & $\mathrm{R}$ \\
Vancomycin & $\mathrm{R}$ & $\mathrm{R}$ & $\mathrm{R}$ \\
Chloramphenicol & $\mathrm{R}$ & $\mathrm{R}$ & $\mathrm{R}$ \\
Cephadroxil & $\mathrm{R}$ & $\mathrm{R}$ & $\mathrm{R}$ \\
Lincomycin & $\mathrm{R}$ & $\mathrm{R}$ & $\mathrm{R}$ \\
Ciphalexin & $\mathrm{R}$ & $\mathrm{R}$ & $\mathrm{R}$ \\
Ceftazidine & $\mathrm{R}$ & $\mathrm{R}$ & $\mathrm{R}$ \\
Cephadroxil & $\mathrm{R}$ & $\mathrm{R}$ & $\mathrm{R}$ \\
\hline
\end{tabular}

$S$, sensitive; $R$, resistance; I, intermediate.

wsp4 is the presence of aminoglycoside phosphotransferase while this enzyme is absent in wsp3 hence probably explaining the differences observed in kanamycin resistance in these isolates.

\section{Carotenoid Isolation and Spectroscopic Characterization}

In the present manuscript, we isolated carotenoids from three haloarchaeal strains (Figures 3A,B). The visible cell pellet color of wsp1 was different when compared to both wsp3, and wsp4 suggesting either variations in the content or molecular structure of the carotenoids produced by these strains (Figure 3A). For further analysis, we purified carotenoids following Yatsunami et al. (2014) protocol and characterized them using UV-visible spectroscopy. UV-visible spectra suggested that wsp1, wsp3, and wsp4 have a similar absorption spectrum having major absorption peaks at 476,502, and $535 \mathrm{~nm}$, however, there were differences in the peak heights (Figure 3B). These differences may explain why carotenoids isolated from wsp 1 are different in color compared to wsp3 and wsp4. These three major peaks correspond to bacterioruberin $(535 \mathrm{~nm})$, all-Trans-lycopene $(502 \mathrm{~nm})$, and 13 -cis-lycopene $(476 \mathrm{~nm})$. Bacterioruberin is a major component of haloarchaeal carotenoids which is synthesized from lycopene (Yang et al., 2015). We took the ratio of peak1/peak3 which may help us understand the bacterioruberin and lycopene contents in these strains. The lycopene has specific absorption at 502 and $476 \mathrm{~nm}$ while bacterioruberin absorbs at $535 \mathrm{~nm}$. A slight absorption of bacterioruberin is also reported at $466 \mathrm{~nm}$. The peak1/peak3 ratio was $1.0,0.9$, and 0.8 for wsp1, wsp3, and wsp4, respectively, suggesting that wsp 1 has the highest bacterioruberin content among the three strains.

\section{Recombinant Expression and Purification of Halotolerant $\alpha$-Amylase From the Isolates}

Haloarchaea lives in hypersaline environments such as marine salterns, saline soils, soda lakes, salted foods, etc. The cell lysis of marine planktons such as shrimps, diatoms, algae, fish, purple 


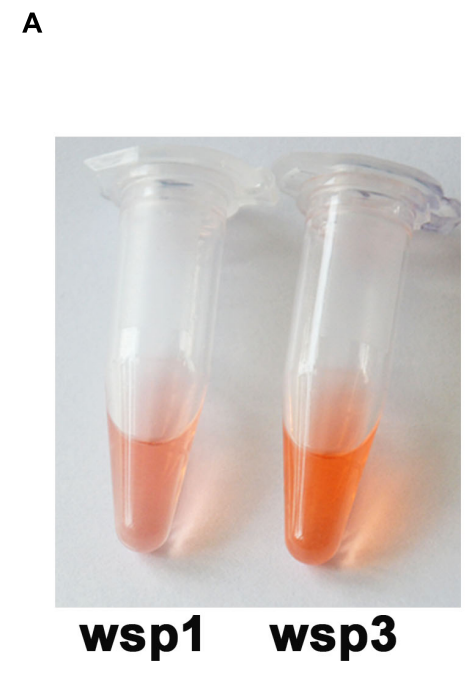

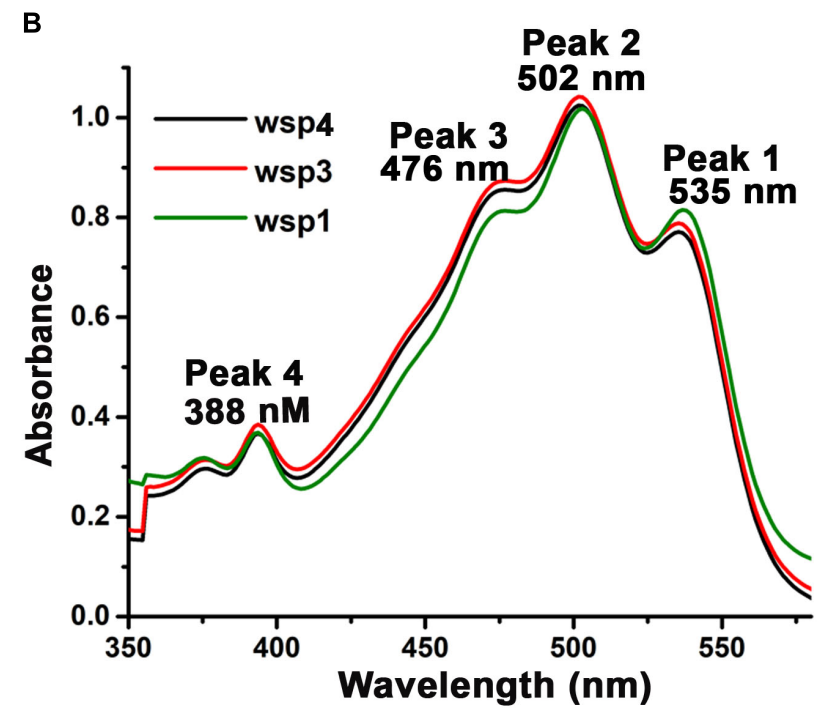

FIGURE 3 | Isolation and biophysical characterization of haloarchaeal carotenoids isolated from wsp1, wsp3, and wsp4 isolates. (A) The microcentrifuge tubes containing purified carotenoids from equal culture volume of the two haloarchaeal strains showing observable color variations. (B) UV-visible absorption spectra of the purified carotenoids showing four carotenoid standard peaks (peak I-IV) at 535, 502, 476, and $388 \mathrm{~nm}$.

and green bacteria, etc. release different biomolecules including starch, cellulose, proteins, chitin, etc. To digest this biopolymer, haloarchaea needs to produce different digestive enzymes to utilize these substrates.

The whole-genome sequencing and annotation results suggested that wsp1, wsp3, wsp4 genomes code for two, one, and three putative $\alpha$-amylase genes, respectively. We successfully cloned all four $\alpha$-amylase genes sharing $<40 \%$ sequence identity among themselves. However, only one of them, named amy 2 (locus tag G3A49-11660) isolated from wsp1, expressed well. Multiple domain analysis of Amy2 (protein ID QIB80089.1) suggested that it has a conserved $\alpha$-amylase domain in the C-terminal region (residue range 227 to 635). A PSI-BLAST search using the NCBI database was performed for the additional $\mathrm{N}$-terminal region (residue ranges from 1 to $226 \mathrm{aa}$ ). However, we did not find any significant hits, therefore, the function of this N-terminal domain is still not clear. Initially, we attempted to purify recombinant His-tagged Amy2 from the cytosolic fraction using E. coli Rosetta DE3 as an expression host. We successfully purified Amy2, however, the purified enzyme was inactive as suggested by the starch agar plate assay. Since most of the amylases are secretory proteins so we cloned amy 2 in pET22b vector having pelB secretion signal sequence at the $\mathrm{N}$-terminus to aid secretion /expression in the periplasmic space and C-terminal $6 \mathrm{X}$ His-tag to aid purification of the recombinant Amy2. We used this construct for purification and further biochemical characterization of Amy2.

\section{Biochemical Characterization of Amy2}

Upon induction, we observed amylase activity even in the cellfree culture supernatant (Figure 4A). E. coli cells alone or cells carrying the pET-22b vector without amylase genes were used as negative controls in these experiments (Figure 4A).
We successfully purified Amy2 from the periplasmic space using Ni-NTA-based affinity chromatography (Figure 4B). The gel-filtration profile suggested that Amy2 is predominantly monomeric in solution (Figure 4C) and enzymatically active on the starch agar plates. We initially tested Amy2 salt tolerance by incubating purified enzyme for $12 \mathrm{~h}$ with different concentrations of salt ranging from 0.25 to $4 \mathrm{M}$ on the starch agar plate (Figure 4D). We observed amylase activity in all the samples suggesting halotolerant property of Amy2. We further performed the biochemical characterization of Amy2 to study its stability and activity at various salt concentrations, $\mathrm{pH}$, and temperature.

\section{Effect of Salt Concentration on Enzyme Activity}

The effect of $\mathrm{NaCl}$ concentration ranging from 0-4 $\mathrm{M}$ on enzyme activity was examined. Data suggests that Amy2 is active in all the $\mathrm{NaCl}$ concentrations studied having maximum activity at $1 \mathrm{M} \mathrm{NaCl}$ concentration. These results suggest that Amy2 has wide-range salt tolerance and retains moderate activity even at $3 \mathrm{M} \mathrm{NaCl}$ concentrations (Figure 4E).

\section{Effect of pH on Enzyme Activity}

The effect of $\mathrm{pH}$ on activity was observed by performing enzyme assay under $\mathrm{pH}$ ranging from 3.0 to 11.0 at 1 unit interval for $30 \mathrm{~min}$ at $37^{\circ} \mathrm{C}$. The maximum enzymatic activity was observed at $\mathrm{pH} 6.0$, while $\sim 30 \%$ activity was observed at $\mathrm{pH} 5.0$ and $\mathrm{pH} 9.0$ suggesting enzyme is active at wide $\mathrm{pH}$ range (Figure 4F).

\section{Effect of Temperature on Enzyme Activity}

The thermal effect on enzymatic activity was studied at the temperature range of $5-75^{\circ} \mathrm{C}$. Our finding revealed that 
A

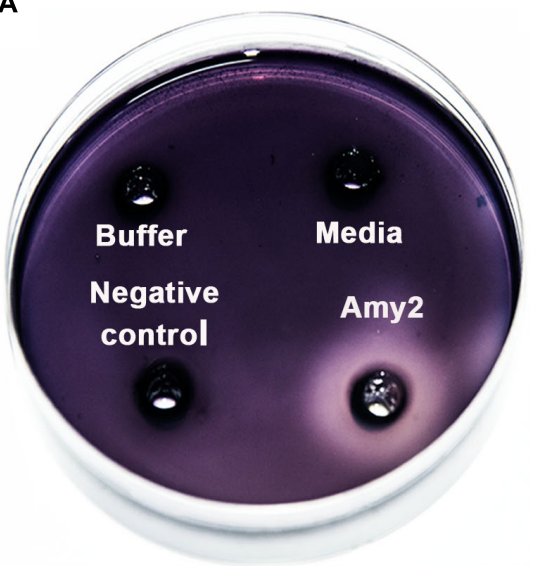

D

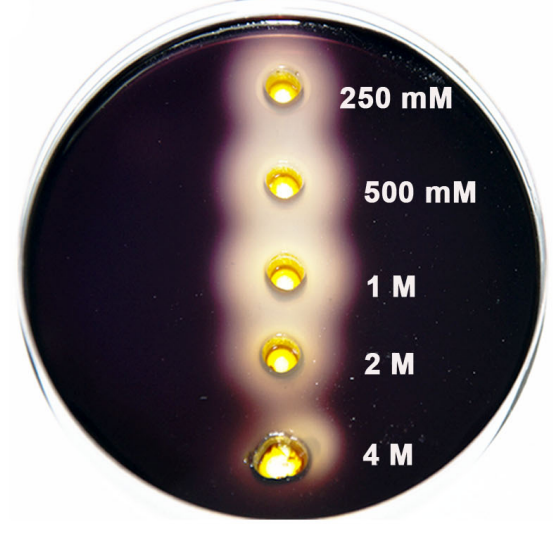

$\mathbf{F}$

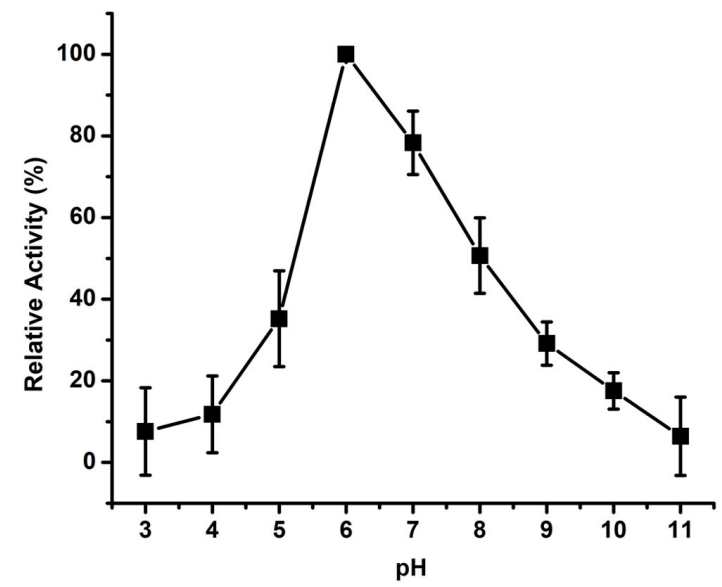

B

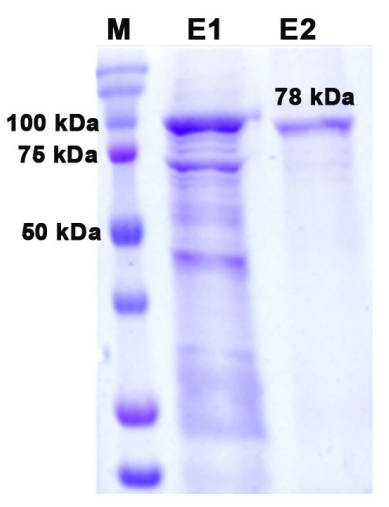

C

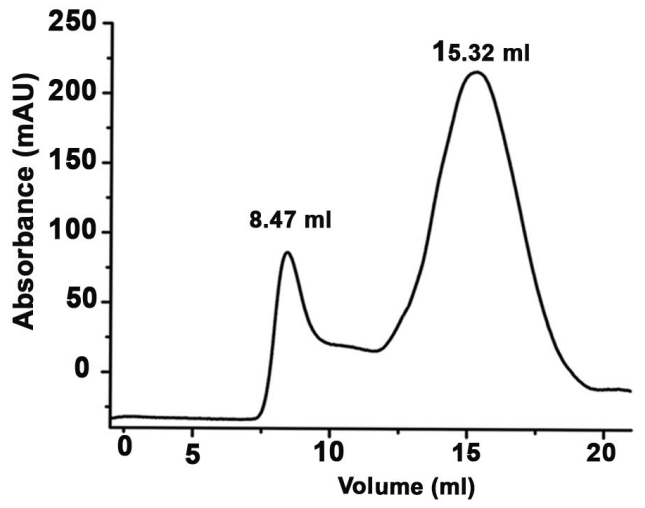

E
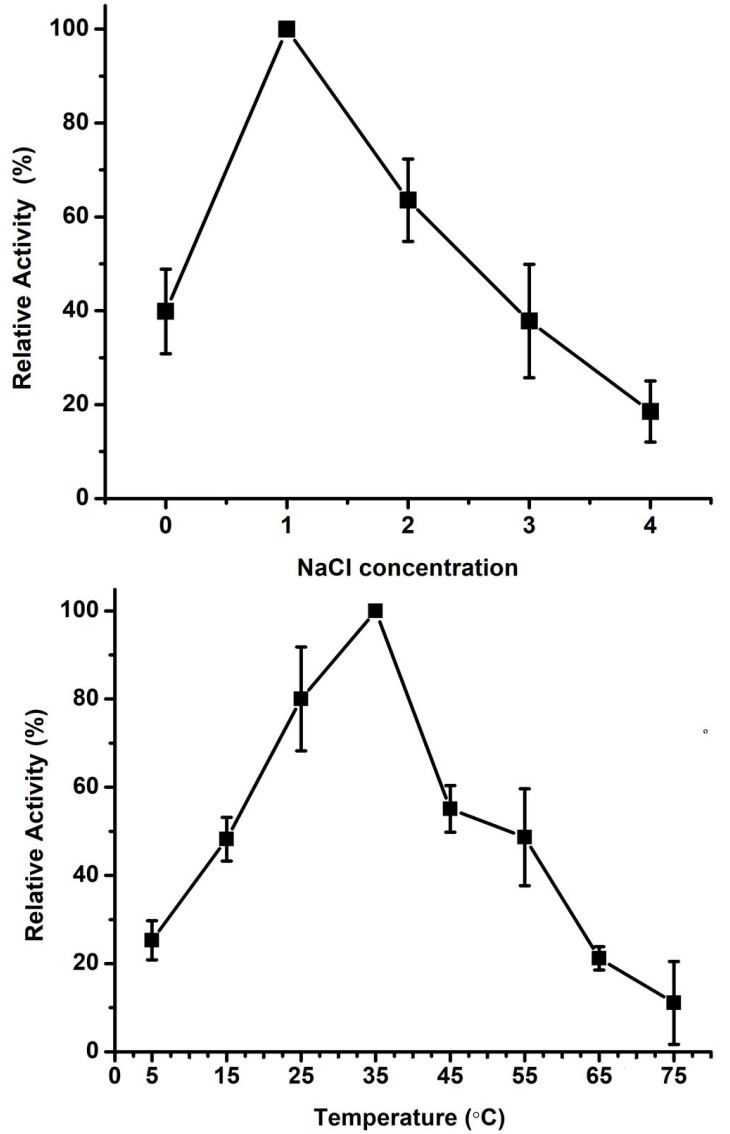

FIGURE 4 | The purification of recombinant $\alpha$-amylase from E. coli, and carotenoids from wild type cultures. (A) The $\alpha$-amylase activity observed from the cell-free supernatant of $E$. coli expressing recombinant Amy2. (B) The $15 \%$ SDS-PAGE showing a predominant protein band at the expected molecular weight of $\sim 78 \mathrm{kDa}$ in the gradient of imidazole elution fractions (E1, E2, E3 correspond to 20, 100, and $200 \mathrm{mM}$ imidazole, respectively). (C) The analytical gel filtration profile suggests that Amy2 is predominantly monomeric in solution. A small fraction, corresponding to large aggregates, was also observed in the void volume (8.47 ml).

(D) Evaluating salt tolerance of Amy2 using starch plate assay suggests that the enzyme is halotolerant. (E) The enzymatic activity of Amy2 against soluble starch was assayed by the iodine-starch method at the various concentrations of $\mathrm{NaCl}$. Relative activity was defined as the percentage of maximum activity at $1 \mathrm{M} \mathrm{NaCl}$. Plots showing effect of $\mathrm{pH}(\mathbf{F})$ and temperature $(\mathbf{G})$ on the Activity of Amy2 and the relative activity was defined as the percentage of maximum activity observed at $\mathrm{pH} 6.0$ or $35^{\circ} \mathrm{C}$, respectively. All activity assays were performed three times in triplicate and mean value with standard deviation are plotted.

Amy2 showed maximum activity at $35^{\circ} \mathrm{C}$, and retained $40 \%$ activity at $55^{\circ} \mathrm{C}$ whereas negligible activity was observed at $75^{\circ} \mathrm{C}$ (Figure 4G).
The biochemical characterization reveals attractive features of Amy2 including halotolerant, moderately thermostable, and activity at a wide $\mathrm{pH}$ range suitable for various industrial 
applications. These biochemical characteristics reported here are comparable to $\alpha$-amylases reported from other halophiles (Onodera et al., 2013; Bajpai et al., 2015).

\section{Structure Prediction and Analysis of Amy2}

Most of the archaeal $\alpha$-amylases belong to the subfamily of glycosyl hydrolase GH families: GH13, GH70, and GH77 (Dong et al., 1997; Bowers et al., 2009). In recent years, several potential $\alpha$-amylases from different halophilic archaea have also been added to these families (Lombard et al., 2014; Santorelli et al., 2016). The enzyme belonging to this families should have three distinct domains: a central catalytic domain harboring a $(\beta / \alpha)_{8}$ Tim barrel (domain $\left.A\right)$, with an irregular loop domain (domain $\mathrm{B}$ ) usually protruding as a long loop out of the barrel connecting the third $\beta$-strand and the third $\alpha$-helix and with the typical structure of an antiparallel $\beta$-sandwich (domain C) (Sarian et al., 2017).

Multiple sequence alignment using the NCBI blast portal revealed that Amy2 has a catalytic $\alpha$-amylase domain encompassing 267-600 residue range (Figure 5A). This catalytic domain is mainly present in archaeal and bacterial species and is known to hydrolyze $\alpha-(1,4)$ glycosidic linkages of glycogen, starch, related polysaccharides, and some oligosaccharides (Antranikian, 1992; Gupta et al., 2003; Sivaramakrishnan et al., 2006). The structural model of the catalytic domain of Amy2 (R269-D625) was built using PHYRE2 (Kelley et al., 2015) webserver suggested that it may have a similar structural architecture found in other members of GH family of amylases i.e., eight stranded alpha/beta-barrel that contains the active site, calcium-binding domain present between beta-strand 3rd and alpha-helix 3rd, and a carboxyl-terminal Greek key beta-barrel domain (Abe et al., 2005). Amy2 sequence blast at the RCSB database (Bernstein et al., 1977) suggested that Halothermothrix orenii $\alpha$-amylase is the closest structural homolog sharing $28 \%$ sequence identity over 426 residues (ranges from 3 to 429 aa) (Figure 5B). The majority of the $\alpha$-amylase enzymes are calcium-dependent metalloenzymes, where metal ion is required for both stability and enzymatic activity (Hsiu et al., 1964; Boel et al., 1990). H. orenii $\alpha$-amylase (PDB ID-1WZA) harbors two different calcium-binding loops, loop 1: Asp44 aa to Ile52 aa and loop 2: Asp65 to Asp73 residues (Sivakumar et al., 2006). The sequence alignment and predicted structural model suggests that the calcium-binding loop 2 is missing in Amy2 (Figures 5B,C). Amy 2 also has smaller B and C domains compared to $H$. orenii $\alpha$-amylase due to deletions in the loop regions (Figures 5B,C).

For amylase activity, a catalytic triad consisting of AspGlu-Asp is required where first aspartic acid is involved in attacking the sugar anomeric center by a nucleophilic side chain and this reaction is assisted and governed by other two Glu-Asp residues (Hsiu et al., 1964; Machius et al., 1995). In H. orenii this triad is composed of Asp224-Glu260-Asp330. Multiple sequence alignment-based analysis suggests that Amy2 also has similar tried consisting of Asp436-Glu463-Asp529, respectively (Figure 5D).

\section{Screening of CRISPR Sequences and Secondary Metabolites}

The clustered regularly interspaced short palindromic repeats (CRISPR)-Cas system is used by bacteria and archaea to fend off foreign genetic elements (Horvath and Barrangou, 2010). Since its discovery, it has been developed into numerous applications like genome editing and regulation of transcription in eukaryotes and bacteria (Gilbert et al., 2013). The genomes of the strains wsp1, wsp3, and wsp4 were submitted to CRISPR Finder ${ }^{1}$ (Grissa et al., 2007) which suggested that all three genomes have multiple CRISPR-DR (CRISPR-direct repeat) as well as spacer sequences. In wsp1, wsp3 and wsp4 genomes six, one, and four CRISPR-DR sequences were observed, respectively (Supplementary Table S3). Whole-genome data of wsp1, wsp3, and wsp4 were further analyzed for the presence of CRISPR associated genes (Cas). Our analysis suggested the presence of several Cas sequences in both wsp1 and wsp4 genomes although no Cas-related genes were identified in the wsp3 genome. In haloarchaea CRISPR-Cas system type I, subtype I-B, is dominantly present (Maier et al., 2017). A characteristic feature of type I systems is the presence of nuclease Cas3 protein, and subtype I-B is further characterized by the presence of Cas8b (Makarova and Koonin, 2015). The functional process of Type I-B system is mainly based on the presence of Cas proteins, namely, Cas5, Cas7, and Cas $8 \mathrm{~b}$ which combine to form a Cascade (CRISPR-associated complex for antiviral defense)like complex in different Haloferax species such as $H$. volcanii (Maier et al., 2019). Genome analysis of both wsp1 and wsp4 suggested that they encode all the genes required to type I CRISPR system i.e., Cas1, Cas2, Cas3, Cas4, Cas5, Cas6, and Cas $8 \mathrm{~b}$ genes. The presence of both Cas 3 and Cas $8 \mathrm{~b}$ suggests that pws1 and pws4 harbor CRISPR-cas type IB system similar to other haloarchaeal species.

In addition to enzymes, recent studies indicate that archaea can also produce a wide range of small peptides and secondary metabolites (Pietra, 1997; Pettit, 2011; Wang et al., 2019). These small peptides and secondary metabolites could be of considerable interest in biotechnology. For the screening of secondary metabolite production, all three genome sequences were uploaded onto an online antiSMASH server (Medema et al., 2011). The output results predicted multiple copies of two important secondary metabolites i.e., siderophore and terpenes in all three strains (Supplementary Table S4). In the case of wsp3, no siderophore gene was predicted. Siderophores play an important role in iron transport (Neilands, 1995) while the functions of terpenes in haloarchaea are not known yet.

\section{DISCUSSION}

Haloarchaeal genera show huge variations in the diversity within different geographical locations (Oren, 2002; Naghoni et al., 2017). There are several reports which suggest that different haloarchaeal strains were routinely isolated from the different salt areas like solar salterns, brines, salt lakes, salt pans, rock

\footnotetext{
${ }^{1}$ https://crispr.i2bc.paris-saclay.fr/Server/
} 
A

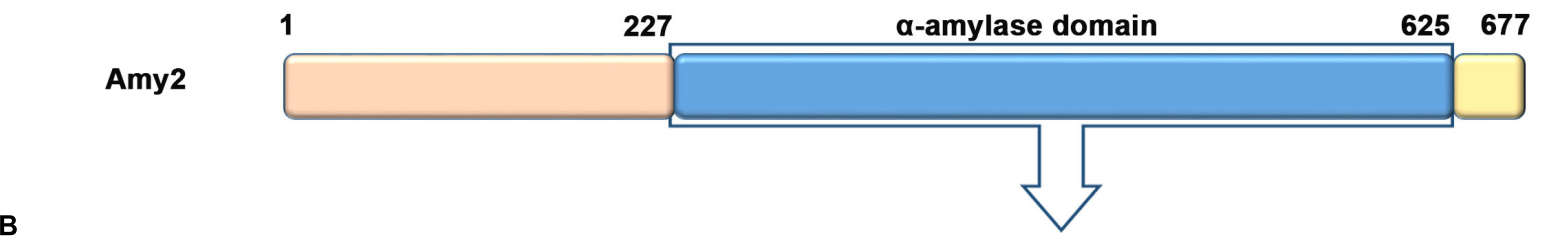

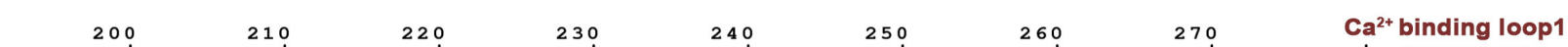

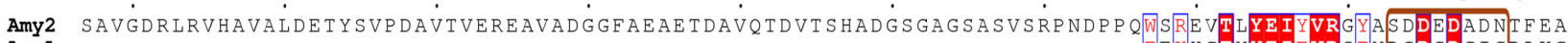

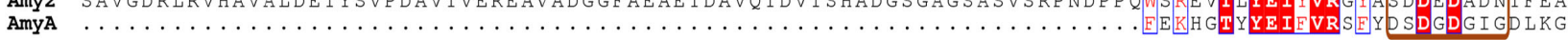

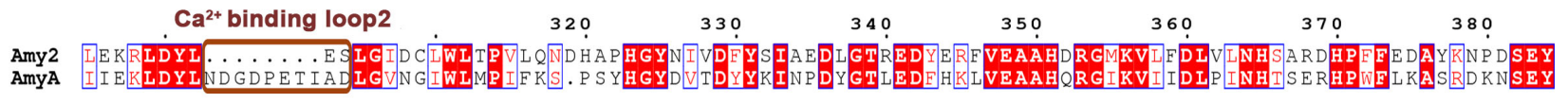

$\begin{array}{cccccc} & 390 & \text { Part of B domain } 400 & 410 & 420 & 430\end{array}$

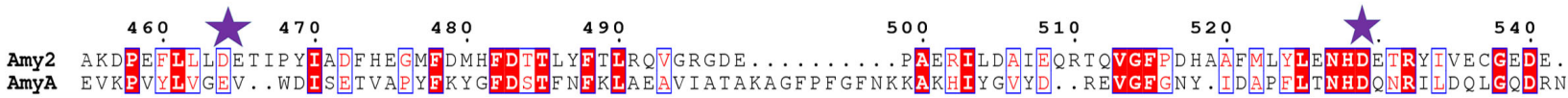
550 560 570 Part of C domain 580 590 600

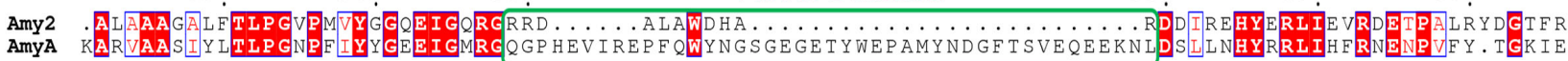
$610 \quad 620 \quad 630 \quad 640 \quad 650 \quad 660 \quad 670$

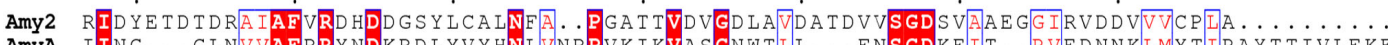

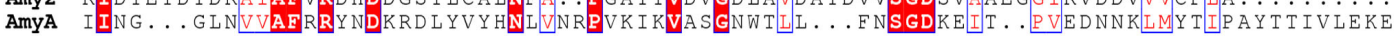

C

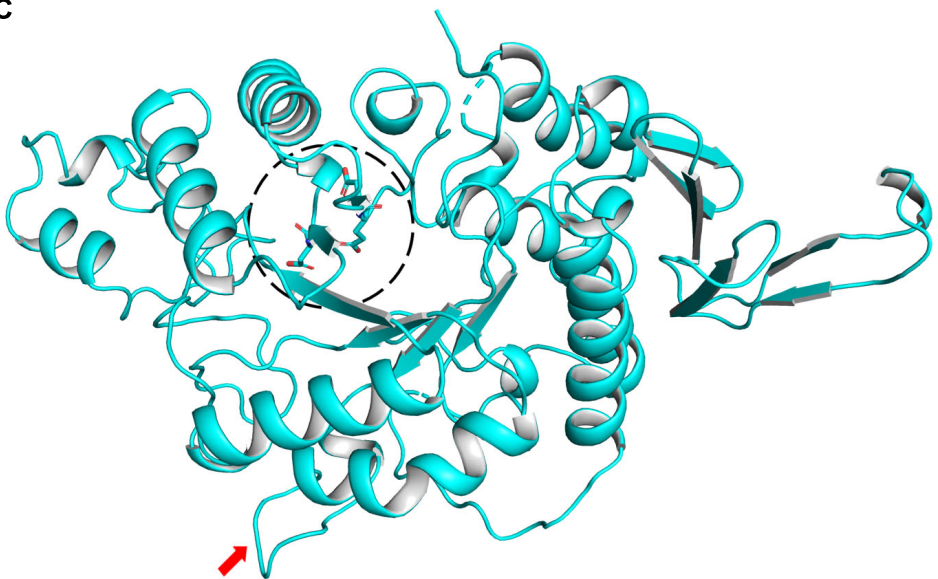

D

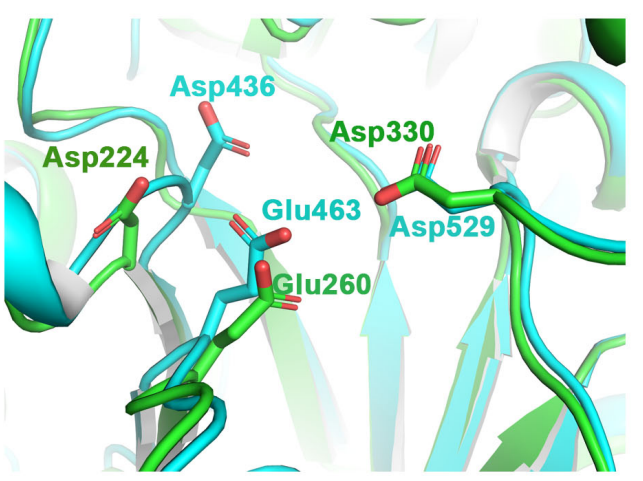

$\mathrm{Ca}^{2+}$ binding loop 2

FIGURE 5 | Structural and sequence features in Amy2. (A) Schematic representation of predicted domain architecture in Amy2. The N-terminal (1-226) region, present in $\alpha$-amylases from other haloarchaeal strains as well, did not show significant sequence similarity with proteins of known function. (B) Multiple sequence alignment of the Amy2 region sharing sequence conservation with $\mathrm{H}$. orenii $\alpha$-amylase. The active site residues are marked in purple stars. The differences in the $\mathrm{Ca}^{2+}$ binding loops, and domains B and C are highlighted in colored boxes. (C) Predicted structural model of Amy2 built using the PHYRE2 online web server. The active site is encircled in black broken circle and active site residues are shown in stick representation. (D) The structural alignment suggested that Amy2 (cyan) and $H$. orenii $\alpha$-amylase (green) have conserved active site triad consisting of structurally equivalent Asp436, Glu463, and Asp529 residues.

salts, etc. (Oren, 2002; Javor, 2012). In the present study, three haloarchaeal strains, namely wsp1, wsp3, and wsp4, were isolated from the high salinity environment and studied in detail.
Haloarchaeal isolates adopt diverse morphological shapes like rods, pleomorphic rods, square, cocci, triangles, and disks (Burns et al., 2007; Minegishi et al., 2010). Few haloarchaeal strains show 
rod form morphology in liquid culture while they are motile and formed nonmotile cocci on solid agar medium (Grant, 2001). All of the three isolates in this study i.e., wsp1, wsp3, and wsp4 were highly pleomorphic. Also, wsp3 and wsp4 were highly vacuolated, which may help these microbes to float on the surface of the water (Oren, 2012).

The pangenome comparison of the four Halogeometricum and twelve Haloferax haloarchaeal genomes, including three isolates reported in this study, have revealed genomic variations resulting from horizontal gene transfer, gene duplication, gene loss events, etc. which is in line with results from other studies (Vos and Didelot, 2009; DeMaere et al., 2013). This data also suggests that pangenomes of these genera are open and each genome contains about 3 to $20 \%$ unique genes. The pangenome analysis further suggested that the distribution of the unique, accessory, and core genes is widespread across different biological functions and no obvious pattern was observed.

Our data and past studies (Nagata et al., 1989; Littlechild, 2015; Karray et al., 2018; Amoozegar et al., 2019) suggest that haloarchaea codes for several enzymes suitable for industrial and research applications. Especially, their salt-tolerant and thermostable nature are attractive features suitable for specific applications like food processing, biofuel production, detergent additives, etc. However, the potential of these enzymes has not yet been commercially exploited. Amylase enzymes are typically involved in essential processes in microorganisms, such as hydrolysis of starch and glycogen, yielding glucose and maltose (Werries and Muller, 1986). There is an increased interest in exploiting amylases for the conversion of grain starch into fermentable sugars for ethanol production (Shigechi et al., 2004; Prakash and Jaiswal, 2010). However, purification of enzymes from the natural haloarchaeal source will not be commercially viable owing to the poor yield and slow growth rate (doubling time $\sim 4-10 \mathrm{~h}$ ). Hence, there is a need for developing processes based on the recombinant expression of the target enzymes using fast-growing microbial hosts like E. coli. There are limited studies that report the recombinant haloarchaeal $\alpha$-amylase production (Perez-Pomares et al., 2003; Hutcheon et al., 2005; Bajpai et al., 2015; Santorelli et al., 2016). Onodera et al., produced recombinant Haloarcula japonica $\alpha$-amylase using E. coli host and found that malA is a cytosolic halotolerant $\alpha$-amylase which is active even at $4 \mathrm{M}$ salt concentration (Onodera et al., 2013). Our whole-genome data analysis of the wsp isolates suggested that they all code for one or more types of $\alpha$-amylase genes in their genomes. We were able to successfully clone, express, and purify one of the annotated $\alpha$-amylase genes named amy 2 from wsp1. Interestingly, though soluble, Amy2 purified from the cytosolic soluble fraction was not active. $\alpha$-amylases are usually secretory proteins and there are five cysteine residues in Amy2. So, to direct the protein to the periplasmic space for proper folding and functional expression, we cloned Amy2 having pelB signal sequence at the $\mathrm{N}$-terminus. Using this strategy, we were successful in purifying active Amy2. In future, this strategy may aid purification of other functional $\alpha$-amylases as well. The purified Amy2 was studied for its activity in the presence of varying salt concentration, $\mathrm{pH}$, and temperature conditions. Data suggests that Amy2 was active in a wide range of salt concentrations, temperature, and $\mathrm{pH}$ conditions. However, detailed studies are required to further investigate its suitability for various industrial applications.

All three isolates were characterized based on a battery of biochemical tests and their antibiotic susceptibility was also evaluated. The results for these assays for wsp1, wsp3, and wsp4 were similar to their corresponding type strains. However, some differences were also observed which we were able to explain based on the whole genome sequencing data analysis. These discrepancies were easily correlated with the presence or absence of the corresponding enzyme(s) in the genome as described in the results section. Haloarchaea is known for producing high levels of carotenoids like bacterioruberin and its C50-related pigments having high commercial potential in various industries including cosmetic, food, poultry and health (Vilchez et al., 2011; MataGomez et al., 2014; Naziri et al., 2014; Rodrigo-Banos et al., 2015). Interestingly, haloarchaeal carotenoid has also been shown to have dose-dependent cytotoxicity against human liver cancer cell lines suggesting anti-cancer activity (Rodrigo-Banos et al., 2015). The isolated carotenoids from all of the three strains in this studies showed a characteristic absorption profile similar to other haloarchaeal strains (Yatsunami et al., 2014; Yang et al., 2015). The differences in the UV-Vis spectrum observed among the carotenoids purified from these strains suggest differences in the contents of bacterioruberin and other carotenoids.

To summarize, we have characterized three haloarchaeal strains isolated from Indian solar salterns. We identified several commercially important enzymes encoded in these three haloarchaeal strains and successfully purified halotolerant recombinant $\alpha$-amylase using $E$. coli as an expression host. Haloarchaea is known to survive harsh environmental and nutrition depleted conditions. The detailed biochemical and biophysical characterization, in the future, may also help explore the feasibility of these enzymes for commercial applications. The future studies aimed at deciphering the function of hypothetical unique and accessory genes may also help in identifying the mechanisms of stress adaptation that aid survival of haloarchaea in harsh conditions.

\section{MATERIALS AND METHODS}

\section{Isolation and Biochemical Characterization of Haloarchaeal Isolates}

For all the biochemical tests, respective basal mediums (composition: $250.0 \mathrm{~g} \mathrm{NaCl}, 20.0 \mathrm{~g} \mathrm{MgSO}_{4} .7 \mathrm{H}_{2} \mathrm{O}, 3.0 \mathrm{~g}$ trisodium citrate $2 \mathrm{H}_{2} \mathrm{O}, 2.0 \mathrm{~g} \mathrm{KCl}, 10.0 \mathrm{~g}$ peptone, $25.0 \mathrm{~g}$ agar in $1000 \mathrm{ml}$; $\mathrm{pH}$ 7.2) were supplemented with a final concentration of $25.0 \%$ $\mathrm{NaCl}$. The growth of the isolates was tested at 12, 15, 20, 25, 30,37 , and $42^{\circ} \mathrm{C}$ on Halovibrio agar (1\% agar added to basal medium). Isolates were plated on Halovibrio medium (without $\mathrm{NaCl}$ ) (HiMedia) supplemented with different concentrations of $\mathrm{NaCl}(2,5,7,10,12,15,18,20,22,25,27$ and 30\%) to test salt tolerance. Growth at different $\mathrm{pH}(5.0,6.5,7.0,8.0,9.0$, and 10.0) was examined using Halovibrio medium (without $\mathrm{NaCl}$ ) 
supplemented with $25 \% \mathrm{NaCl}$ as described earlier (Chen et al., 2016). The $\mathrm{pH}$ was adjusted using different buffers: MES ( $\mathrm{pH}$ 5.0-6.0), PIPES (pH 6.5-7.0), HEPES ( $\mathrm{pH} 7.5-8.0$ ), and CHES ( $\mathrm{pH}$ 9.0-10). Catalase activity, citrate utilization (using Simmons' citrate agar) and urea hydrolysis were determined as described by Cowan and Steel (Cowan and Steel, 1965). The hydrolysis of casein, gelatin, starch and indole, methyl red test, VogesProskauer test and oxidase activity were assessed as described by Smibert and Krieg (Smibert et al., 1994). Nitrate reduction was tested as described by Lanyi (Lányi, 1988). Acid production from various sugars was tested on minimal medium by using the method described by Smith et al. (Sasser, 1990). The utilization of different carbohydrates as sole carbon source was tested in minimal medium supplemented with $25.0 \% \mathrm{NaCl}$ and $2 \%$ $\mathrm{MgSO}_{4} 7 \mathrm{H}_{2} \mathrm{O}$ with $1 \%$ different carbon sources.

\section{The Whole-Genome Sequencing and $16 S$ rRNA Comparison}

Genomic DNA extractions were performed using the Zymogen DNA isolation kit (Cat. No. D6105). The 16S rRNA gene sequences of strain wsp1, wsp3, and wsp4 were PCR-amplified using 21 forward (TCCGGTTGATCCYGCCGG) and 1453 reverse (GGGCYGCACGCGYRCTACA) standard primers. The amplified 16S rRNA gene sequences were further aligned with those of representative related taxa using the EzTaxon server (Yoon et al., 2017). The 16S rRNA gene sequences of wsp1, wsp3, and wsp4 representatives closely related species were retrieved from the EzTaxon server (Chun et al., 2007) and aligned using MEGA version X (Tamura et al., 2004; Kumar et al., 2018). Phylogenetic trees were constructed using the neighborjoining methods (Saitou and Nei, 1987) and the percentage of replicate trees in which the associated taxa clustered together in the bootstrap test (1500 replicates) are shown next to the branches (Felsenstein, 1985). The whole-genome sequencing of all three strains were performed using Illumina NextSeq and for assembly CLC NGS Cell ver 9 (CGWB) were used. The draft genomes were annotated using the RAST online server (Aziz et al., 2008). The H. borinquense DSM 11551 and H. volcanii DS2 genomes were used as a reference for comparison and annotation. Pangenome analysis was carried out by using the BPGA pipeline (Chaudhari et al., 2016). The genomes were screened for secondary metabolite gene clusters using antiSMASH online server (Medema et al., 2011).

\section{Genome-Sequence Submission}

The genome sequence of wsp1, wsp3, and wsp4 are submitted at NCBI under accession numbers as NZ_CP048738, NZ_CP050274 and NZ_CP048739.

\section{Transmission Electron Microscopy}

Aliquots of $50 \mu \mathrm{l}$ from samples containing wild type culture (basal medium supplemented with $25.0 \% \mathrm{NaCl}$ ) were pipetted on a carbon-coated 300-mesh copper grid (Polysciences, United States). The excess sample was blotted and followed by air drying. The grids were further imaged using a JEM 2100 electron microscope, operated at $200 \mathrm{keV}$ (JEOL).

\section{Cloning, Expression and Purification of Amy2}

The full length of amy2 was amplified and cloned in pET22b (Novagen) over-expression vector between NdeI-XhoI and NcoI-XhoI sites to yield recombinant protein having C-terminal 6X His-tag. The first set of restrictions were used for cytosolic expression (NdeI-XhoI) while the other set was used to express Amy2 fused with pelB (NcoI-XhoI) secretion signal sequence at the N-terminal. Forward primers 5'AGCTCATATGGCTGTCGGCGAGTCAGTA and 5'AGTAC CATGGCTGTCGGCGAGTCAGTA having NdeI and NcoI sites, respectively, and reverse primer 5'AGTCCTCGAGGGCGAGC GGGCAGACGAC having XhoI site were used for gene amplification. The amplified PCR products and vector were digested with NdeI-XhoI and NcoI-XhoI sites followed by an overnight ligation at $4^{\circ} \mathrm{C}$. The ligated products were transformed into Top10 chemical competent cells (Thermo Scientific, United States). Positive clones were screened using colony PCR method. The positive clones were further confirmed by DNA sequencing. The protein was expressed using BL21-DE3 Rosetta cells (Thermo Scientific, United States). Transformed cells were inoculated into $10 \mathrm{ml}$ media as a primary and then into $1000 \mathrm{ml}$ media supplemented $100 \mu \mathrm{g} / \mathrm{ml}$ ampicillin. The cultures were induced at $0.6 \mathrm{OD}_{600}$ by adding $0.3 \mathrm{mM}$ IPTG and incubated overnight at $18^{\circ} \mathrm{C}$. Amy2 was purified using $\mathrm{Ni}$ NTA (Merk-Sigma, United States) based affinity chromatography method following standard manufacturer's instructions. Cell pellets were dissolved in buffer A (20 mM Tris pH 7.4, $250 \mathrm{mM}$ $\mathrm{NaCl}$ and $10 \mathrm{mM} \mathrm{CaCl}_{2}$ ) and lysed by sonication. The sample was centrifuged at 12,000 g for $30 \mathrm{~min}$. After centrifugation, pellet was discarded and the cell free supernatant was mixed with Ni-NTA resin. Protein was eluted by adding increasing the concentration of imidazole $(20-500 \mathrm{mM})$ to the buffer A. The eluted fractions were loaded on $15 \%$ SDS PAGE to check purity and quality of the protein samples. The elution fractions were pooled and concentrated using $30 \mathrm{~K}$ centrifugal amicon ultrafiltration devices (Merk Millipore, United States). The protein was further purified using gel filtration chromatography using Superdex 200 Increase column. The purified Amy2 was used for further biochemical experiments.

\section{Analytical Gel Filtration}

The $0.5 \mathrm{ml}$ of the purified protein sample was injected into the Superdex 200 Increase (GE Healthcare, United States) analytical gel filtration column pre-equilibrated with $20 \mathrm{mM}$ Tris $\mathrm{pH}$ 7.4, $250 \mathrm{mM} \mathrm{NaCl}$ and $10 \mathrm{mM} \mathrm{CaCl}_{2}$. The flow rate was kept at $0.5 \mathrm{ml}$ per min. The chromatogram was recorded at both 280 and $220 \mathrm{~nm}$.

\section{Carotenoid Isolation}

The carotenoids were extracted by following protocol published by Yatsunami et al. (2014). Briefly, $20 \mathrm{ml}$ of haloarchaeal cultures were centrifuged at $12,000 \mathrm{~g}$ for $30 \mathrm{~min}$ at $25^{\circ} \mathrm{C}$. The supernatant was discarded and pellets were further resuspended in $5 \mathrm{ml}$ of acetone and methanol solution (7:3). This solution was incubated at room temperature for 
$30 \mathrm{~min}$ in dark followed by centrifugation at $12,000 \mathrm{~g}$ for 30 min. Reddish-pink supernatant was collected and pellets were discarded. Isolated colored supernatants were centrifuged at $3000 \mathrm{~g}$ in the speed-vac (Eppendorf concentrator plus) to remove methanol and acetone. The Reddish-pink colored pellets were finally dissolved in $200 \mu \mathrm{l}$ of $100 \%$ methanol. UV spectra of extracted solutions were recorded at 200-700 nm range using a spectrophotometer (CECIL CE7500).

\section{Enzymatic Assay on a Starch Agar Plate}

The $\alpha$-amylase activity of the heterologously expressed Amy2 was measured using a starch agar plate assay. $1 \mathrm{gm}$ of starch agar was dissolved in $100 \mathrm{ml}$ of distilled water and poured into petriplates. $50 \mu \mathrm{l}$ of $5 \mu \mathrm{M}$ purified Amy2 was loaded into starch agar wells and incubated overnight at $37^{\circ} \mathrm{C}$. The activity was checked by staining the plates with an iodine solution [15\% solution containing $5 \%(\mathrm{wt} / \mathrm{v}) \mathrm{I}_{2}$ and $10 \%(\mathrm{wt} / \mathrm{v}) \mathrm{KI}$.

\section{Biochemical Characterization of Amy2}

Biochemical characterization of the enzyme was performed by the iodine-starch method. The reaction solution of $50 \mu \mathrm{l}$ contained $1.0 \mathrm{ISU} / \mathrm{ml}$ enzyme and $0.2 \%(\mathrm{w} / \mathrm{v})$ starch in reaction buffer $\left(20 \mathrm{mM}\right.$ Tris- $\mathrm{HCl}, 250 \mathrm{mM} \mathrm{NaCl}$ and $10 \mathrm{mM} \mathrm{CaCl}_{2}, \mathrm{pH}$ 7.4). $A_{660}$ was measured by standard enzyme assay. The effect of temperature on enzyme activity was determined by incubating the enzyme at the temperature range of $5-75^{\circ} \mathrm{C}$ at $10^{\circ} \mathrm{C}$ intervals for 30 mins. Optimum $\mathrm{pH}$ for enzyme activity was determined by measuring the activity at $37^{\circ} \mathrm{C}$ for 30 min under different $\mathrm{pH}$ conditions at an interval of $1.0 \mathrm{pH}$ unit. Sodium acetate buffer was used for $\mathrm{pH} 3-5$, phosphate buffer was used for $\mathrm{pH} \mathrm{6-7,} \mathrm{Tris}$ buffer was used for $\mathrm{pH} 8-9$, and sodium bicarbonate buffer was used for $\mathrm{pH} 10-11$. Effect of salt concentration was observed by examining the activity at different $\mathrm{NaCl}$ concentration (0-4 M) at $37^{\circ} \mathrm{C}$ for $30 \mathrm{~min}$. The data presented is an average of three independent experiments.

\section{Evolutionary Relationships of Taxa}

The evolutionary history was inferred using the Neighbor-Joining method (Saitou and Nei, 1987). The optimal tree with the sum of branch length $=0.23099238$ is shown. The percentage of replicate trees in which the associated taxa clustered together in the bootstrap test (1500 replicates) is shown next to the branches. The tree is drawn to scale, with branch lengths in the same units as those of the evolutionary distances used to infer the phylogenetic tree. The evolutionary distances were computed using the Maximum Composite Likelihood method and are in the units of the number of base substitutions per site. This analysis involved 16 nucleotide sequences. All ambiguous positions were removed for each sequence pair (pairwise deletion

\section{REFERENCES}

Abe, A., Yoshida, H., Tonozuka, T., Sakano, Y., and Kamitori, S. (2005). Complexes of Thermoactinomyces vulgaris R-47 alpha-amylase 1 and pullulan model oligossacharides provide new insight into the mechanism for recognizing substrates with alpha- $(1,6)$ glycosidic linkages. FEBS J. 272, 6145-6153. doi: 10.1111/j.1742-4658.2005.05013.x option). There were a total of 1483 positions in the final dataset. Evolutionary analyses were conducted in software suite MEGA X (Kumar et al., 2018).

\section{DATA AVAILABILITY STATEMENT}

Publicly available datasets were analyzed in this study. This data can be found here: GCA_900112175.1, GCA_900115785.1, GCA_000172995.2, GCA_000337835.1, GCA_000337815.1, GCA_000306765.2, GCA_000337795.1, GCA_000336815.1, GCA_000336955.1, GCA_001190965.1, GCA_000336755.1, GCA_000336735.1, GCA_000336795.1, GCA_000025685.1, GCA_001368915.1, and GCA_000337095.1.

\section{AUTHOR CONTRIBUTIONS}

KT, SP, and DV conceived the study. KT, SP, and AP coordinated the study. SP provided the strains. KT and DV designed experiments, analyzed the data, and wrote the manuscript with inputs from other co-authors. DV, GV, and CS performed experiments. All authors reviewed the results and approved the final version of the manuscript.

\section{FUNDING}

This work was supported by grants to KT, SP, and AP by Council of Scientific and Industrial Research, India. DV and GV are recipient of senior research fellowship from Council of Scientific and Industrial Research and University Grants Commission, India, respectively.

\section{ACKNOWLEDGMENTS}

The authors thank Mr. Surinder Singh, Mr. Randeep Singh, and Mr. Davender Singh at CSIR-IMTECH Chandigarh for supporting Laboratory experiments. KT would like to acknowledge members of Structural Biology Laboratory for useful suggestions and discussions.

\section{SUPPLEMENTARY MATERIAL}

The Supplementary Material for this article can be found online at: https://www.frontiersin.org/articles/10.3389/fmicb. 2020.02082/full\#supplementary-material

Alikhan, N. F., Petty, N. K., Ben Zakour, N. L., and Beatson, S. A. (2011). BLAST ring image generator (BRIG): simple prokaryote genome comparisons. BMC Genomics 12:402. doi: 10.1186/1471-2164-12-402

Amoozegar, M. A., Safarpour, A., Noghabi, K. A., Bakhtiary, T., and Ventosa, A. (2019). Halophiles and their vast potential in biofuel production. Front. Microbiol. 10:1895. doi: 10.3389/fmicb.2019. 01895 
Anderson, I., Scheuner, C., Goker, M., Mavromatis, K., Hooper, S. D., Porat, I., et al. (2011). Novel insights into the diversity of catabolic metabolism from ten haloarchaeal genomes. PLoS One 6:e20237. doi: 10.1371/journal.pone.0020237

Antranikian, G. (1992). Microbial Degradation of Natural Products, ed. G. Winkelmann Weinheim: VCH.

Aziz, R. K., Bartels, D., Best, A. A., Dejongh, M., Disz, T., Edwards, R. A., et al. (2008). The RAST server: rapid annotations using subsystems technology. BMC Genomics 9:75. doi: 10.1186/1471-2164-9-75

Bajpai, B., Chaudhary, M., and Saxena, J. (2015). Production and Characterization of alpha-amylase from an extremely halophilic archaeon, haloferax sp. HA10. Food Technol. Biotechnol. 53, 11-17. doi: 10.17113/ftb.53.01.15.3824

Becker, E. A., Seitzer, P. M., Tritt, A., Larsen, D., Krusor, M., Yao, A. I., et al. (2014). Phylogenetically driven sequencing of extremely halophilic archaea reveals strategies for static and dynamic osmo-response. PLoS Genet. 10:e1004784. doi: 10.1371/journal.pgen.1004784

Bernstein, F. C., Koetzle, T. F., Williams, G. J., Meyer, E. F. Jr., Brice, M. D., et al. (1977). The protein data bank. A computer-based archival file for macromolecular structures. Eur. J. Biochem. 80, 319-324. doi: 10.1111/j.14321033.1977.tb11885.x

Boel, E., Brady, L., Brzozowski, A. M., Derewenda, Z., Dodson, G. G., Jensen, V. J., et al. (1990). Calcium binding in alpha-amylases: an X-ray diffraction study at 2.1-A resolution of two enzymes from Aspergillus. Biochemistry 29, 6244-6249. doi: 10.1021/bi00478a019

Borchert, E., Knobloch, S., Dwyer, E., Flynn, S., Jackson, S. A., Johannsson, R., et al. (2017). Biotechnological potential of cold adapted Pseudoalteromonas spp. Isolated from 'Deep Sea' Sponges. Mar. Drugs 15:184. doi: 10.3390/md15060184

Bowers, K. J., Mesbah, N. M., and Wiegel, J. (2009). Biodiversity of polyextremophilic Bacteria: does combining the extremes of high salt, alkaline $\mathrm{pH}$ and elevated temperature approach a physico-chemical boundary for life? Saline Syst. 5:9. doi: 10.1186/1746-1448-5-9

Bowers, K. J., and Wiegel, J. (2011). Temperature and pH optima of extremely halophilic archaea: a mini-review. Extremophiles 15, 119-128. doi: 10.1007/ s00792-010-0347-y

Britton, G. (1995). Structure and properties of carotenoids in relation to function. FASEB J. 9, 1551-1558. doi: 10.1096/fasebj.9.15.8529834

Burns, D. G., Janssen, P. H., Itoh, T., Kamekura, M., Li, Z., Jensen, G., et al. (2007). Haloquadratum walsbyi gen. nov., sp. nov., the square haloarchaeon of Walsby, isolated from saltern crystallizers in Australia and Spain. Int. J. Syst. Evol. Microbiol. 57, 387-392. doi: 10.1099/ijs.0.64690-0

Capes, M. D., Dassarma, P., and Dassarma, S. (2012). The core and unique proteins of haloarchaea. BMC Genomics 13:39. doi: 10.1186/1471-2164-13-39

Chaudhari, N. M., Gupta, V. K., and Dutta, C. (2016). BPGA- an ultra-fast pan-genome analysis pipeline. Sci. Rep. 6:24373.

Chen, S., Liu, H. C., Zhou, J., and Xiang, H. (2016). Halorubrum pallidum sp. nov., an extremely halophilic archaeon isolated from a subterranean rock salt. Int. J. Syst. Evol. Microbiol. 66, 2980-2986. doi: 10.1099/ijsem.0.001129

Chi, M. C., Chen, Y. H., Wu, T. J., Lo, H. F., and Lin, L. L. (2010). Engineering of a truncated alpha-amylase of Bacillus sp. strain TS-23 for the simultaneous improvement of thermal and oxidative stabilities. J. Biosci. Bioeng. 109, 531538. doi: 10.1016/j.jbiosc.2009.11.012

Chun, J., Lee, J. H., Jung, Y., Kim, M., Kim, S., Kim, B. K., et al. (2007). EzTaxon: a web-based tool for the identification of prokaryotes based on 16S ribosomal RNA gene sequences. Int. J. Syst. Evol. Microbiol. 57, 2259-2261. doi: 10.1099/ ijs.0.64915-0

Cibrario, A., Peanne, C., Lailheugue, M., Campbell-Sills, H., and Dols-Lafargue, M. (2016). Carbohydrate metabolism in Oenococcus oeni: a genomic insight. BMC Genomics 17:984. doi: 10.1186/s12864-016-3338-2

Cowan, S. T., and Steel, K. J. (1965). Manual for the identification of medical bacteria. J. Clin. Pathol. 46:975.

DeMaere, M. Z., Williams, T. J., Allen, M. A., Brown, M. V., Gibson, J. A., Rich, J., et al. (2013). High level of intergenera gene exchange shapes the evolution of haloarchaea in an isolated Antarctic lake. Proc. Natl. Acad. Sci. U.S.A. 110, 16939-16944. doi: 10.1073/pnas.1307090110

Dong, G., Vieille, C., Savchenko, A., and Zeikus, J. G. (1997). Cloning, sequencing, and expression of the gene encoding extracellular alpha-amylase from Pyrococcus furiosus and biochemical characterization of the recombinant enzyme. Appl. Environ. Microbiol. 63, 3569-3576. doi: 10.1128/aem.63.9.35693576.1997
Falb, M., Muller, K., Konigsmaier, L., Oberwinkler, T., Horn, P., Von Gronau, S., et al. (2008). Metabolism of halophilic archaea. Extremophiles 12, 177-196.

Felsenstein, J. (1985). Confidence limits on phylogenies: an approach using the bootstrap. Evolution 39, 783-791. doi: 10.1111/j.1558-5646.1985.tb 00420.x

Fiedor, J., and Burda, K. (2014). Potential role of carotenoids as antioxidants in human health and disease. Nutrients 6, 466-488. doi: 10.3390/nu60 20466

Flowers, T. J., and Colmer, T. D. (2015). Plant salt tolerance: adaptations in halophytes. Ann. Bot. 115, 327-331. doi: 10.1093/aob/mcu267

Giani, M., Garbayo, I., Vilchez, C., and Martinez-Espinosa, R. M. (2019). Haloarchaeal carotenoids: healthy novel compounds from extreme environments. Mar. Drugs 17:524. doi: 10.3390/md17090524

Gilbert, L. A., Larson, M. H., Morsut, L., Liu, Z., Brar, G. A., Torres, S. E., et al. (2013). CRISPR-mediated modular RNA-guided regulation of transcription in eukaryotes. Cell 154, 442-451. doi: 10.1016/j.cell.2013.06.044

Grant, W. (2001). Class III. Halobacteria class nov. Bergey’s Manual Syst. Bacteriol. $1,294-301$.

Grant, W., and Larsen, H. (1989). Extremely halophilic archaeobacteria, order Halobacteriales ord. nov. Bergey's Manual Syst. Bacteriol. 3, 2216-2228.

Grissa, I., Vergnaud, G., and Pourcel, C. (2007). CRISPRFinder: a web tool to identify clustered regularly interspaced short palindromic repeats. Nucleic Acids Res. 35, W52-W57.

Gruber, C., Legat, A., Pfaffenhuemer, M., Radax, C., Weidler, G., Busse, H. J., et al. (2004). Halobacterium noricense sp. nov., an archaeal isolate from a bore core of an alpine Permian salt deposit, classification of Halobacterium sp. NRC-1 as a strain of H. salinarum and emended description of H. salinarum. Extremophiles 8, 431-439. doi: 10.1007/s00792-004-0403-6

Gunde-Cimerman, N., Oren, A., and Plemenitas, A. (2005). Adaptation to Life at High Salt Concentrations in Archaea, Bacteria and Eukarya. New York, NY: Kluwer Academic Publishers, 9.

Gupta, R., Gigras, P., Mohapatra, H., Goswami, V. K., and Chauhan, B. (2003). Microbial $\alpha$-amylases: a biotechnological perspective. Process Biochem. 38, 1599-1616. doi: 10.1016/s0032-9592(03)00053-0

Horvath, P., and Barrangou, R. (2010). CRISPR/Cas, the immune system of bacteria and archaea. Science 327, 167-170. doi: 10.1126/science.1179555

Hsiu, J., Fischer, E. H., and Stein, E. A. (1964). Alpha-amylases as calciummetalloenzymes. Ii. Calcium and the catalytic activity. Biochemistry 3, 61-66. doi: 10.1021/bi00889a011

Hutcheon, G. W., Vasisht, N., and Bolhuis, A. (2005). Characterisation of a highly stable alpha-amylase from the halophilic archaeon Haloarcula hispanica. Extremophiles 9, 487-495. doi: 10.1007/s00792-005-0471-2

Javor, B. J. (2012). Hypersaline Environments: Microbiology and Biogeochemistry. Berlin: Springer Science \& Business Media.

Karray, F., Ben Abdallah, M., Kallel, N., Hamza, M., Fakhfakh, M., and Sayadi, S. (2018). Extracellular hydrolytic enzymes produced by halophilic bacteria and archaea isolated from hypersaline lake. Mol. Biol. Rep. 45, 1297-1309. doi: 10.1007/s11033-018-4286-5

Kelley, L. A., Mezulis, S., Yates, C. M., Wass, M. N., and Sternberg, M. J. (2015). The Phyre2 web portal for protein modeling, prediction and analysis. Nat. Protoc. 10, 845-858. doi: 10.1038/nprot.2015.053

Kim, Y. B., Kim, J. Y., Song, H. S., Lee, C., Ahn, S. W., Lee, S. H., et al. (2018). Novel haloarchaeon Natrinema thermophila having the highest growth temperature among haloarchaea with a large genome size. Sci. Rep. 8:7777.

Kumar, S., Stecher, G., Li, M., Knyaz, C., and Tamura, K. (2018). MEGA X: molecular evolutionary genetics analysis across computing platforms. Mol. Biol. Evol. 35, 1547-1549. doi: 10.1093/molbev/msy096

Lányi, B. (1988). 1 Classical and rapid identification methods for medically important bacteria. Methods Microbiol. 19, 1-67. doi: 10.1016/s0580-9517(08) 70407-0

Littlechild, J. A. (2015). Archaeal enzymes and applications in industrial biocatalysts. Archaea 2015:147671.

Lombard, V., Golaconda Ramulu, H., Drula, E., Coutinho, P. M., and Henrissat, B. (2014). The carbohydrate-active enzymes database (CAZy) in 2013. Nucleic Acids Res. 42, D490-D495.

Machius, M., Wiegand, G., and Huber, R. (1995). Crystal structure of calciumdepleted Bacillus licheniformis alpha-amylase at 2.2 A resolution. J. Mol. Biol. 246, 545-559. 
Maier, L.-K., Alkhnbashi, O. S., Backofen, R., and Marchfelder, A. (2017). "CRISPR and Salty: CRISPR-Cas Systems in Haloarchaea," in RNA Metabolism and Gene Expression in Archaea, Nucleic Acids and Molecular Biology, Vol. 32, ed. B. Clouet-d'Orval (Cham: Springer), 243-269. doi: 10.1007/978-3-319-65795-0_ 11

Maier, L. K., Stachler, A. E., Brendel, J., Stoll, B., Fischer, S., Haas, K. A., et al. (2019). The nuts and bolts of the Haloferax CRISPR-Cas system I-B. RNA Biol. 16, 469-480. doi: 10.1080/15476286.2018.1460994

Makarova, K. S., and Koonin, E. V. (2015). Annotation and classification of CRISPR-Cas systems. Methods Mol. Biol. 1311, 47-75. doi: 10.1007/978-14939-2687-9_4

Mata-Gomez, L. C., Montanez, J. C., Mendez-Zavala, A., and Aguilar, C. N. (2014). Biotechnological production of carotenoids by yeasts: an overview. Microb. Cell Fact. 13:12. doi: 10.1186/1475-2859-13-12

Medema, M. H., Blin, K., Cimermancic, P., De Jager, V., Zakrzewski, P., Fischbach, M. A., et al. (2011). antiSMASH: rapid identification, annotation and analysis of secondary metabolite biosynthesis gene clusters in bacterial and fungal genome sequences. Nucleic Acids Res. 39, W339-W346.

Minegishi, H., Kamekura, M., Itoh, T., Echigo, A., Usami, R., and Hashimoto, T. (2010). Further refinement of the phylogeny of the Halobacteriaceae based on the full-length RNA polymerase subunit B'(rpoB') gene. Int. J. Syst. Evol. Microbiol. 60, 2398-2408. doi: 10.1099/ijs.0.017160-0

Montalvo-Rodriguez, R., Vreeland, R. H., Oren, A., Kessel, M., Betancourt, C., and Lopez-Garriga, J. (1998). Halogeometricum borinquense gen. nov., sp. nov., a novel halophilic archaeon from Puerto Rico. Int. J. Syst. Bacteriol. 48(Pt 4), 1305-1312. doi: 10.1099/00207713-48-4-1305

Montero-Lobato, Z., Ramos-Merchante, A., Fuentes, J. L., Sayago, A., FernandezRecamales, A., Martinez-Espinosa, R. M., et al. (2018). Optimization of growth and carotenoid production by haloferax mediterranei using response surface methodology. Mar. Drugs 16:372. doi: 10.3390/md16100372

Mormile, M. R., Biesen, M. A., Gutierrez, M. C., Ventosa, A., Pavlovich, J. B., Onstott, T. C., et al. (2003). Isolation of Halobacterium salinarum retrieved directly from halite brine inclusions. Environ. Microbiol. 5, 1094-1102. doi: 10.1046/j.1462-2920.2003.00509.x

Nagata, S., Hyde, C. C., and Miles, E. W. (1989). The alpha subunit of tryptophan synthase. Evidence that aspartic acid 60 is a catalytic residue and that the double alteration of residues 175 and 211 in a second-site revertant restores the proper geometry of the substrate binding site. J. Biol. Chem. 264, 6288-6296.

Naghoni, A., Emtiazi, G., Amoozegar, M. A., Cretoiu, M. S., Stal, L. J., Etemadifar, Z., et al. (2017). Microbial diversity in the hypersaline Lake Meyghan, Iran. Sci. Rep. 7:11522.

Narsing Rao, M. P., Xiao, M., and Li, W. J. (2017). Fungal and bacterial pigments: secondary metabolites with wide applications. Front. Microbiol. 8:1113. doi: 10.3389/fmicb.2017.01113

Naziri, D., Hamidi, M., Hassanzadeh, S., Tarhriz, V., Maleki Zanjani, B., Nazemyieh, H., et al. (2014). Analysis of carotenoid production by Halorubrum sp. TBZ126; an extremely Halophilic Archeon from Urmia Lake. Adv. Pharm. Bull. 4, 61-67.

Neilands, J. B. (1995). Siderophores: structure and function of microbial iron transport compounds. J. Biol. Chem. 270, 26723-26726. doi: 10.1074/jbc.270. 45.26723

Ollivier, B., Caumette, P., Garcia, J. L., and Mah, R. A. (1994). Anaerobic bacteria from hypersaline environments. Microbiol. Rev. 58, 27-38. doi: 10.1128/mmbr. 58.1.27-38.1994

Onodera, M., Yatsunami, R., Tsukimura, W., Fukui, T., Nakasone, K., Takashina, T., et al. (2013). Gene analysis, expression, and characterization of an intracellular alpha-amylase from the extremely halophilic archaeon Haloarcula japonica. Biosci. Biotechnol. Biochem. 77, 281-288. doi: 10.1271/bbb.120693

Oren, A. (2002). Molecular ecology of extremely halophilic Archaea and Bacteria. FEMS Microbiol. Ecol. 39, 1-7. doi: 10.1111/j.1574-6941.2002.tb00900.x

Oren, A. (2010). Industrial and environmental applications of halophilic microorganisms. Environ. Technol. 31, 825-834. doi: 10.1080/ 09593330903370026

Oren, A. (2012). The function of gas vesicles in halophilic archaea and bacteria: theories and experimental evidence. Life 3, 1-20. doi: 10.3390/life3010 001
Oren, A., Ventosa, A., and Grant, W. (1997). Proposed minimal standards for description of new taxa in the order Halobacteriales. Int. J. Syst. Evol. Microbiol. 47, 233-238. doi: 10.1099/00207713-47-1-233

Papke, R. T., Corral, P., Ram-Mohan, N., De La Haba, R. R., Sanchez-Porro, C., Makkay, A., et al. (2015). Horizontal gene transfer, dispersal and haloarchaeal speciation. Life 5, 1405-1426. doi: 10.3390/life5021405

Perez-Pomares, F., Bautista, V., Ferrer, J., Pire, C., Marhuenda-Egea, F. C., and Bonete, M. J. (2003). Alpha-amylase activity from the halophilic archaeon Haloferax mediterranei. Extremophiles 7, 299-306. doi: 10.1007/s00792-0030327-6

Pettit, R. K. (2011). Culturability and secondary metabolite diversity of extreme microbes: expanding contribution of deep sea and deep-sea vent microbes to natural product discovery. Mar. Biotechnol. 13, 1-11. doi: 10.1007/s10126-0109294-y

Pietra, F. (1997). Secondary metabolites from marine microorganisms: bacteria, protozoa, algae and fungi. Achievements and prospects. Nat. Prod. Rep. 14, 453-464.

Prakash, O., and Jaiswal, N. (2010). alpha-Amylase: an ideal representative of thermostable enzymes. Appl. Biochem. Biotechnol. 160, 2401-2414. doi: 10. 1007/s12010-009-8735-4

Radax, C., Gruber, C., and Stan-Lotter, H. (2001). Novel haloarchaeal 16S rRNA gene sequences from Alpine Permo-Triassic rock salt. Extremophiles 5, 221228. doi: $10.1007 / \mathrm{s} 007920100192$

Rodrigo-Banos, M., Garbayo, I., Vilchez, C., Bonete, M. J., and MartinezEspinosa, R. M. (2015). Carotenoids from Haloarchaea and their potential in biotechnology. Mar. Drugs 13, 5508-5532. doi: 10.3390/md13095508

Saitou, N., and Nei, M. (1987). The neighbor-joining method: a new method for reconstructing phylogenetic trees. Mol. Biol. Evol. 4, 406-425.

Santorelli, M., Maurelli, L., Pocsfalvi, G., Fiume, I., Squillaci, G., La Cara, F., et al. (2016). Isolation and characterisation of a novel alpha-amylase from the extreme haloarchaeon Haloterrigena turkmenica. Int. J. Biol. Macromol. 92, 174-184. doi: 10.1016/j.ijbiomac.2016.07.001

Sarian, F. D., Janecek, S., Pijning, T., Ihsanawati, Nurachman, Z., Radjasa, O. K., et al. (2017). A new group of glycoside hydrolase family 13 alpha-amylases with an aberrant catalytic triad. Sci. Rep. 7:44230.

Sasser, M. (1990). Identification of Bacteria by Gas Chromatography of Cellular Fatty Acids. Newark, DE: MIDI Inc.

Schiraldi, C., Giuliano, M., and De Rosa, M. (2002). Perspectives on biotechnological applications of archaea. Archaea 1, 75-86. doi: 10.1155/2002/ 436561

Schubert, B. A., Lowenstein, T. K., Timofeeff, M. N., and Parker, M. A. (2010). Halophilic Archaea cultured from ancient halite, Death Valley, California. Environ. Microbiol. 12, 440-454. doi: 10.1111/j.1462-2920.2009.02086.x

Shigechi, H., Koh, J., Fujita, Y., Matsumoto, T., Bito, Y., Ueda, M., et al. (2004). Direct production of ethanol from raw corn starch via fermentation by use of a novel surface-engineered yeast strain codisplaying glucoamylase and alphaamylase. Appl. Environ. Microbiol. 70, 5037-5040. doi: 10.1128/aem.70.8.50375040.2004

Singh, A., and Singh, A. K. (2017). Haloarchaea: worth exploring for their biotechnological potential. Biotechnol. Lett. 39, 1793-1800. doi: 10.1007/ s10529-017-2434-y

Sivakumar, N., Li, N., Tang, J. W., Patel, B. K., and Swaminathan, K. (2006). Crystal structure of AmyA lacks acidic surface and provide insights into protein stability at poly-extreme condition. FEBS Lett. 580, 2646-2652. doi: 10.1016/j. febslet.2006.04.017

Sivaramakrishnan, S., Gangadharan, D., Nampoothiri, K. M., Soccol, C. R., and Pandey, A. (2006). a-Amylases from microbial sources-an overview on recent developments. Food Technol. Biotechnol. 44, 173-184.

Smibert, R., Krieg, N., Gerhardt, P., Murray, R., and Wood, W. (1994). Methods for General and Molecular Bacteriology. Washington DC: American Society for Microbiology.

Soppa, J. (2006). From genomes to function: haloarchaea as model organisms. Microbiology 152, 585-590. doi: 10.1099/mic.0.28504-0

Stan-Lotter, H., and Fendrihan, S. (2015). Halophilic Archaea: life with desiccation, radiation and oligotrophy over geological times. Life 5, 1487-1496. doi: 10. 3390/life5031487 
Tamura, K., Nei, M., and Kumar, S. (2004). Prospects for inferring very large phylogenies by using the neighbor-joining method. Proc. Natl. Acad. Sci. U.S.A. 101, 11030-11035. doi: 10.1073/pnas.0404206101

Tettelin, H., Masignani, V., Cieslewicz, M. J., Donati, C., Medini, D., Ward, N. L., et al. (2005). Genome analysis of multiple pathogenic isolates of Streptococcus agalactiae: implications for the microbial "pan-genome". Proc. Natl. Acad. Sci. U.S.A. 102, 13950-13955.

Torreblanca, M., Rodriguez-Valera, F., Juez, G., Ventosa, A., Kamekura, M., and Kates, M. (1986). Classification of non-alkaliphilic halobacteria based on numerical taxonomy and polar lipid composition, and description of Haloarcula gen. nov. and Haloferax gen. nov. Syst. Appl. Microbiol. 8, 89-99. doi: 10.1016/s0723-2020(86)80155-2

Verma, D. K., Baral, I., Kumar, A., Prasad, S. E., and Thakur, K. G. (2019). Discovery of bacteriorhodopsins in Haloarchaeal species isolated from Indian solar salterns: deciphering the role of the $\mathrm{N}$-terminal residues in protein folding and functional expression. Microb. Biotechnol. 12, 434-446. doi: 10.1111/17517915.13359

Vernikos, G., Medini, D., Riley, D. R., and Tettelin, H. (2015). Ten years of pangenome analyses. Curr. Opin. Microbiol. 23, 148-154. doi: 10.1016/j.mib.2014. 11.016

Vershinin, A. (1999). Biological functions of carotenoids-diversity and evolution. Biofactors 10, 99-104. doi: 10.1002/biof.5520100203

Vilchez, C., Forjan, E., Cuaresma, M., Bedmar, F., Garbayo, I., and Vega, J. M. (2011). Marine carotenoids: biological functions and commercial applications. Mar. Drugs 9, 319-333. doi: 10.3390/md9030319

Vos, M., and Didelot, X. (2009). A comparison of homologous recombination rates in bacteria and archaea. ISME J. 3, 199-208. doi: 10.1038/ismej.2008.93

Wang, S., Zheng, Z., Zou, H., Li, N., and Wu, M. (2019). Characterization of the secondary metabolite biosynthetic gene clusters in archaea. Comput. Biol. Chem. 78, 165-169. doi: 10.1016/j.compbiolchem.2018.11.019

Werries, E., and Muller, F. (1986). Studies on the substrate specificity of alpha- and beta-amylase of Entamoeba histolytica. Mol. Biochem. Parasitol. 18, 211-221. doi: 10.1016/0166-6851(86)90039-3

Winters, Y. D., Lowenstein, T. K., and Timofeeff, M. N. (2015). Starvation-survival in Haloarchaea. Life 5, 1587-1609. doi: 10.3390/life5041587
Wolf, Y. I., Makarova, K. S., Yutin, N., and Koonin, E. V. (2012). Updated clusters of orthologous genes for Archaea: a complex ancestor of the Archaea and the byways of horizontal gene transfer. Biol. Direct. 7:46. doi: 10.1186/1745-61 50-7-46

Wu, S., Zhu, Z., Fu, L., Niu, B., and Li, W. (2011). WebMGA: a customizable web server for fast metagenomic sequence analysis. BMC Genomics 12:444. doi: 10.1186/1471-2164-12-444

Yang, Y., Yatsunami, R., Ando, A., Miyoko, N., Fukui, T., Takaichi, S., et al. (2015). Complete biosynthetic pathway of the C50 carotenoid bacterioruberin from lycopene in the extremely halophilic archaeon Haloarcula japonica. J. Bacteriol. 197, 1614-1623. doi: 10.1128/jb. 02523-14

Yatsunami, R., Ando, A., Yang, Y., Takaichi, S., Kohno, M., Matsumura, Y., et al. (2014). Identification of carotenoids from the extremely halophilic archaeon Haloarcula japonica. Front. Microbiol. 5:100. doi: 10.3389/fmicb.2014. 00100

Yoon, S. H., Ha, S. M., Kwon, S., Lim, J., Kim, Y., Seo, H., et al. (2017). Introducing EzBioCloud: a taxonomically united database of 16S rRNA gene sequences and whole-genome assemblies. Int. J. Syst. Evol. Microbiol. 67, 1613-1617. doi: 10.1099/ijsem.0.001755

Zhang, J., Sun, Z., Sun, P., Chen, T., and Chen, F. (2014). Microalgal carotenoids: beneficial effects and potential in human health. Food Funct. 5, 413-425.

Conflict of Interest: The authors declare that the research was conducted in the absence of any commercial or financial relationships that could be construed as a potential conflict of interest.

Copyright (c) 2020 Verma, Vasudeva, Sidhu, Pinnaka, Prasad and Thakur. This is an open-access article distributed under the terms of the Creative Commons Attribution License (CC BY). The use, distribution or reproduction in other forums is permitted, provided the original author(s) and the copyright owner(s) are credited and that the original publication in this journal is cited, in accordance with accepted academic practice. No use, distribution or reproduction is permitted which does not comply with these terms. 